\title{
Novel Scabies Mite Serpins Inhibit the Three Pathways of the Human Complement System
}

\author{
Angela Mika ${ }^{1}$, Simone L. Reynolds ${ }^{1,2}$, Frida C. Mohlin ${ }^{3}$, Charlene Willis ${ }^{1}$, Pearl M. Swe ${ }^{1}$, \\ Darren A. Pickering ${ }^{1}$, Vanja Halilovic ${ }^{1}$, Lakshmi C. Wijeyewickrema ${ }^{4}$, Robert N. Pike ${ }^{4}$, Anna M. Blom ${ }^{3}$, \\ David J. Kemp ${ }^{1}$, Katja Fischer ${ }^{1 *}$
}

1 Infectious Diseases Program, Biology Department, Queensland Institute of Medical Research, Brisbane, Queensland, Australia, 2 School of Veterinary Sciences, University of Queensland, Gatton, Queensland, Australia, 3 Department of Laboratory Medicine, Lund University, Malmö, Sweden, 4 Department of Biochemistry and Molecular Biology, Monash University, Melbourne, Victoria, Australia

\begin{abstract}
Scabies is a parasitic infestation of the skin by the mite Sarcoptes scabiei that causes significant morbidity worldwide, in particular within socially disadvantaged populations. In order to identify mechanisms that enable the scabies mite to evade human immune defenses, we have studied molecules associated with proteolytic systems in the mite, including two novel scabies mite serine protease inhibitors (SMSs) of the serpin superfamily. Immunohistochemical studies revealed that within mite-infected human skin SMSB4 (54 kDa) and SMSB3 (47 kDa) were both localized in the mite gut and feces. Recombinant purified SMSB3 and SMSB4 did not inhibit mite serine and cysteine proteases, but did inhibit mammalian serine proteases, such as chymotrypsin, albeit inefficiently. Detailed functional analysis revealed that both serpins interfered with all three pathways of the human complement system at different stages of their activation. SMSB4 inhibited mostly the initial and progressing steps of the cascades, while SMSB3 showed the strongest effects at the C9 level in the terminal pathway. Additive effects of both serpins were shown at the C9 level in the lectin pathway. Both SMSs were able to interfere with complement factors without protease function. A range of binding assays showed direct binding between SMSB4 and seven complement proteins ( 1 , properdin, MBL, C4, C3, C6 and C8), while significant binding of SMSB3 occurred exclusively to complement factors without protease function $(\mathrm{C} 4, \mathrm{C} 3, \mathrm{C} 8)$. Direct binding was observed between SMSB4 and the complement proteases $\mathrm{C} 1 \mathrm{~s}$ and $\mathrm{C} 1 \mathrm{r}$. However no complex formation was observed between either mite serpin and the complement serine proteases C1r, C1s, MASP-1, MASP-2 and MASP-3. No catalytic inhibition by either serpin was observed for any of these enzymes. In summary, the SMSs were acting at several levels mediating overall inhibition of the complement system and thus we propose that they may protect scabies mites from complement-mediated gut damage.
\end{abstract}

Citation: Mika A, Reynolds SL, Mohlin FC, Willis C, Swe PM, et al. (2012) Novel Scabies Mite Serpins Inhibit the Three Pathways of the Human Complement System. PLoS ONE 7(7): e40489. doi:10.1371/journal.pone.0040489

Editor: Charaf Benarafa, University of Bern, Switzerland

Received February 17, 2012; Accepted June 7, 2012; Published July 11, 2012

Copyright: (c) 2012 Mika et al. This is an open-access article distributed under the terms of the Creative Commons Attribution License, which permits unrestricted use, distribution, and reproduction in any medium, provided the original author and source are credited.

Funding: This work was supported by the Australian National Health and Medical Research Council (http://www.nhmrc.gov.au/), Program Grant 496600, Project Grant 613626 and a fellowship to DJK. AB would like to acknowledge the financial support of the Swedish Research Council (K2009-68X-14928-06-3), the Swedish Foundation for Strategic Research and the Knut and Alice Wallenberg and Inga-Britt and Arne Lundberg Foundations. The funders had no role in study design, data collection and analysis, decision to publish, or preparation of the manuscript.

Competing Interests: The authors have declared that no competing interests exist.

*E-mail: Katja.Fischer@qimr.edu.au

\section{Introduction}

Scabies is a common transmissible parasitic skin infestation caused by the mite Sarcoptes scabiei. It spreads rapidly under crowded conditions [1] and is a major public health problem in socially disadvantaged communities, such as Australian Indigenous populations and in developing countries [2]. In some remote Australian Aboriginal communities over $70 \%$ of children present to clinics with scabies in their first two years of life, most of them acquiring their first infection at the age of one to two months [3]. Pruritic scabies lesions facilitate opportunistic secondary bacterial infections, particularly with Group A streptococci and Staphylococcus aureus, causing significant sequelae, i.e. cellulitis, septicemia and glomerulonephritis [4] and leading to the most extreme levels of Acute Rheumatic Fever and Rheumatic Heart Disease worldwide [5]. Pyoderma affects more than 111 million children globally, making it one of the three most common skin disorders in children along with scabies and tinea. Despite the alarming numbers, scabies remains a truly neglected infectious disease, which is in part due to the difficulty in obtaining sufficient numbers of mites for molecular studies. Emerging resistance to the currently available therapeutics against scabies, permethrin and ivermectin, emphasizes the need to identify novel drug targets [6].

In the epidermis the human complement system is an immediate host defense, which operates as a network of more than 35 plasma proteins. Activation of the system is triggered by immune complexes, carbohydrates or foreign surfaces and proceeds via one of three enzymatic cascades: the classical (CP), lectin (LP) and alternative (AP) pathways [7]. This leads to opsonisation and phagocytosis of the target, the release of anaphylatoxins, followed by the induction of inflammation and the formation of a membrane attack complex, which creates a pore in the target membrane causing cell lysis. Any successful human pathogen that is in contact with host plasma must have evolved a strategy to resist complement-mediated killing. 
Burrowing scabies mites imbibe epidermal protein and plasma $[8,9]$, containing a multitude of diverse factors of the human innate immunity including complement proteins, such as Clq or C9, which were previously found in the mite gut [10,11]. Thus, the mite has to be equipped with specific mechanisms to protect its gut membrane against the adverse effects of complement activation. Recently, we have characterized a multigene family of proteolytically active and inactive serine proteases $[12,13]$ that are present in the mite digestive system. Two of the catalytically inactive scabies mite proteases were found to interfere with the human complement activation by binding to complement proteins [10]. This resonates with previous observations that many pathogens avoid complement attack or complement-mediated inflammation by evading recognition via antibodies or MBL and/ or by expressing complement inhibitors (reviewed in $[14,15]$ ). Characterization of countermeasures against complement, evolved in hematophagous parasites such as trematodes, nematodes, leeches, mosquitoes, flies, triatomine bugs, ticks and mites, is a rapidly developing research field [16]. Schistosomes for example are exposed to complement in the bloodstream of their definitive hosts and employ several strategies to evade complement on multiple levels of the system [17]. A high turnover of surface antigens and a low intrinsic immunogenicity of the mambranocalyx were proposed as broad mechanisms [18]. Their effects are enhanced by multiple regulatory proteins, some of them acquired from the host, that slow down complement function by binding and inhibiting various complement factors (reviewed in [16]). At the other end of the broad spectrum of blood-feeding parasites, and most closely related to mites, are the acarid ticks [19-21]. Feeding times of ticks vary from less than $1 \mathrm{~h}$ to weeks, implying that they must possess mechanisms to overcome host defenses. The feeding success of a tick depends on its ability to locally suppress the host complement and coagulation systems, and a major adaptation to blood feeding was proposed to be a complex assortment of pharmacologically active saliva components that are released into the bite site [22-24]. To date transcriptomes of twelve tick species have been analysed [25-38], and as anticipated an increasing number of complement-inhibitory molecules are identified, concurrent with the observation of anti-complement activity in tick salivary gland extracts [39].

The complement inhibitor OmCI, a salivary protein released by the soft tick Ornithodoros moubata, [40-42] has been shown to directly bind to the central complement component C5 in a stable complex, thereby inhibiting cleavage of C5 to the anaphylatoxin C5a and the subunit of the membrane attack complex C5b. Further lipocalins with high sequence identity to OmGI have recently been described, namely TSGP2 and TSGP3 in O. Savignyi, and are proposed to target $\mathrm{C} 5$ by a common mechanism of action [43]. Ixodes scapularis and I. ricinus produce a family of homologous Isac-like proteins that behave as regulators primarily of the alternative pathway by preventing C3b and factor B inhibition [44]. Further homologous sequences have been described in several Ixodes species [28,29,45-48]. Tyson et al. investigated the specific mechanism by which one of these homologs, I. scapularis salivary protein 20 (Salp20), inhibits the alternative pathway [49], demonstrating that Salp20 directly binds to the regulatory complement protein properdin, thereby destabilising the complement $\mathrm{C} 3$ convertase $(\mathrm{C} 3 \mathrm{bBb})$ in the alternative complement pathway.

The classical, lectin and alternative complement pathways are activated and controlled by serine proteases. These proteases are endogenously regulated by human serpins [50], which usually function as irreversible inhibitors of serine and occasionally cysteine proteases [51]. Serpins control proteolytic pathways in animals, plants, fungi, bacteria and certain viruses [52] and regulate diverse physiological functions in vertebrates, such as the blood clotting, fibrinolysis, complement, hormone transport and inflammatory responses. The protein superfamily of serpins shows a highly conserved secondary structure [51], consisting of three major $\beta$-sheets, eight to nine $\alpha$-helices, and an exposed reactive center loop (RCL). The RCL is located 30-40 residues from the G-terminus. After binding to the active site of a target protease similarly to a binding substrate, the RCL of an inhibitory serpin is specifically cleaved by the protease. This triggers a major conformational change in the inhibitor that disrupts the active site residues, thus facilitating the formation of an inactive, covalently linked serpin/protease-complex. The specificity and rate of interaction of inhibitory serpins can be regulated by interactions between proteases and cofactors with serpin exosites (reviewed in [51]). In addition, increasing numbers of noninhibitory serpins have been described that use alternative binding sites and/or unknown mechanisms to serve, for example, as chaperones, hormone transporters, tumor suppressors and antiangiogenic factors [52].

It has been previously hypothesized that serpins released with the tick saliva may interfere with host protease cascades involved in innate immunity $[53,54]$. To date over 30 serpin-encoding tick cDNA sequences have been described [54-58], most of them contain signal sequences and are secreted in midgut and salivary glands [56]. Several studies on tick serpins provide evidence that these play important roles in the parasite - host interface and may be valuable targets for tick control. We describe here novel serpins that are secreted into the gut of scabies mites, which feed in the epidermal layers [59]. Skin protein [60] and serum components, such as host immunoglobulins [61] and complement components including C1q [10] and C9 [62], have been localized by immunohistology in the digestive tract of scabies mites infesting human skin. Hence, as seen in ticks, mites presumably have to overcome inflammation, complement activation and blood coagulation to successfully feed. Here we provide evidence that scabies mites may utilize two serpins to manipulate the human complement system.

\section{Methods}

\section{Ethics Statement}

All animals were handled in strict accordance with good animal practice as defined by the Australian code of practice for the care and use of animals for scientific purposes, and the National Health \& Medical Research Council's (NHMRG) Animal Code of Practice. Ethical approval for the production of polyclonal antibodies in mice was obtained from the Queensland Institute of Medical Research Animal Ethics Committee in compliance with the Code of practice, the NHMRC, and the Queensland government responsible authority [63]. Written informed consent was obtained from the crusted scabies patient for the collection of shed skin crusts, with the approval of the Human Research Ethics Committee of the Northern Territory Department of Health and Families and the Menzies School of Health Research.

\section{Cloning}

A sequence analysis of cDNA libraries made from human scabies mites (Sarcoptes scabiei; [64]) revealed several EST clones with high similarities to serpins. The cDNA sequences of two scabies mite serpins (SMSB3a, cDNA clone Yv7088B02; GenBank accession no. JF317220, www.ncbi.nlm.nih.gov/GenBank; SMSB4, cDNA clone Yv5004A04, GenBank accession no. JF317222) were amplified using specific primers (5' AC- 
GGGTCGACGATTGTGATGAAGCTCAATTGGATC, $\quad 3$ ACGGCTGCAGGTAGAATCGATGCACTTCACGGATGAAC) for SMSB3 and (5' ACCGGTCGACAAACGTCAG CACGATTCTCAATCG， 3' ACGGCTGGAGTCATGCAACAATCGCTTGGGATGCATAGGGGGG) for SMSB4, respectively, including the restriction sites $S a l \mathrm{I}$ and $P s t \mathrm{I}$ required for directional cloning into the pQE9 expression vector (Qiagen). The PCR products were digested at these sites, ligated into the vector, and transformed into E.coli XL1-blue (Stratagene; SMSB3) and BL21 (DE3) cells (Qiagen; SMSB4). Transformants were confirmed by DNA sequencing with BigDye 3.1 (Applied Biosystems) using T3 and T7 primers. Serpin names were given according to human homologues and their nomenclature.

\section{Heterologous Expression and Purification of SMSs}

Recombinant proteins were expressed in E. coli and purified under denaturing conditions. Briefly, E. coli cells were cultivated in $\mathrm{LB}$ medium containing $100 \mu \mathrm{g} / \mathrm{mL}$ ampicillin at $37^{\circ} \mathrm{C}$ over night. After inoculation of $2 \mathrm{YT}$ medium containing the same concentration of ampicillin, the cells were grown at $37^{\circ} \mathrm{C}$ until an $\mathrm{OD}_{600}$ of $0.5-0.6$ was reached and expression was induced by addition of $1 \mathrm{mM}$ IPTG for 4 hours. Cells were collected by centrifugation at $4000 \times \mathrm{g}$ at $4^{\circ} \mathrm{C}$ for $20 \mathrm{~min}$, resuspended in $50 \mathrm{mM}$ Tris, $\mathrm{pH} 8.0$, $100 \mathrm{mM} \mathrm{NaCl}, 10 \mathrm{mM}$ EDTA, $1 \mathrm{mM}$ PMSF and lysed in the presence of $250 \mu \mathrm{g} / \mathrm{ml}$ lysozyme and $10 \mu \mathrm{g} / \mathrm{ml}$ DNAse at room temperature under continuous rotation. All of the following purification steps were performed at $4^{\circ} \mathrm{C}$. After sonication of the spheroplasts by a Sonifier 250 (Branson), inclusion bodies were washed six times using $50 \mathrm{mM}$ Tris, pH 8.0, $100 \mathrm{mM} \mathrm{NaCl}$, $10 \mathrm{mM}$ EDTA, $0.5 \%(\mathrm{v} / \mathrm{v})$ Triton X-100 and retrieved by centrifugation $\left(16,000 \times \mathrm{g}\right.$ for $20 \mathrm{~min}$ at $\left.4^{\circ} \mathrm{C}\right)$, followed by solubilisation in $6 \mathrm{M}$ guanidine hydrochloride, $50 \mathrm{mM}$ Tris, $\mathrm{pH} 7.8,1 \mathrm{mM}$ DTT for $60 \mathrm{~min}$. Proteins were further purified by nickel immobilized metal affinity chromatography (Qiagen): Solubilised protein was diluted $1: 1$ with $6 \mathrm{M}$ urea, $100 \mathrm{mM}$ $\mathrm{NaH}_{2} \mathrm{PO}_{4}, 10 \mathrm{mM}$ Tris, pH 8.0, $5 \mathrm{mM}$ imidazole, $150 \mathrm{mM}$ $\mathrm{NaCl}, 1 \%(\mathrm{v} / \mathrm{v})$ glycerol, $1 \mathrm{mM}$ DTT and bound over night to a pre-equilibrated Ni-NTA matrix (Qiagen) on a rotating shaker. The matrix was loaded into a column (PolyPrep, BioRad) and washed with 10 column volumes of $6 \mathrm{M}$ urea, $100 \mathrm{mM}$ $\mathrm{NaH}_{2} \mathrm{PO}_{4}, 10 \mathrm{mM}$ Tris, $\mathrm{pH} 6.3,5 \mathrm{mM}$ imidazole, $150 \mathrm{mM}$ $\mathrm{NaCl}, 1 \%(\mathrm{v} / \mathrm{v})$ glycerol, $1 \mathrm{mM}$ DTT. Bound proteins were eluted using 4 column volumes of $6 \mathrm{M}$ urea, $100 \mathrm{mM} \mathrm{NaH}{ }_{2} \mathrm{PO}_{4}, 10 \mathrm{mM}$ Tris, $\mathrm{pH}$ 8.0, $250 \mathrm{mM}$ imidazole, $150 \mathrm{mM} \mathrm{NaCl}, 1 \%$ (v/v) glycerol and $1 \mathrm{mM}$ DTT. Purified recombinant proteins were refolded for 3 hours in $300 \mathrm{mM}$ L-arginine, $50 \mathrm{mM}$ Tris, $50 \mathrm{mM}$ $\mathrm{NaCl}$ and $5 \mathrm{mM}$ DTT at $\mathrm{pH} 8.0$ for SMSB3 and $\mathrm{pH} 10.5$ for SMSB4 by drop wise addition using a Minipuls 3 pump (Gilson) at a flow rate of $0.03 \mathrm{ml} / \mathrm{min}$ under continuous stirring. Refolded proteins were concentrated using an Ultrasette Lab Tangential Flow Device (10 kDa cut off; PALL Life Sciences), followed by further concentration in centrifugal filters (Amicon Ultra, Millipore). Protein concentrations were determined by Bradford [65]. Molecular masses and purity were confirmed using SDS-PAGE analysis with silver and Coomassie blue R-250 staining. For all following assays, SMSs were buffer exchanged into the corresponding assay buffers using Zeba Desalt Spin columns (Pierce) directly before use. Chemical control experiments were performed for all assays to exclude buffer effects.

\section{Site-directed Mutagenesis}

For functional analysis, the SMSs sequences were systematically mutated in the predicted hinge region [clones A (T368E, A372V) and B (T368P)] and RCL [clones C $(\mathrm{G} 381 \mathrm{H})$ and D (L382P)] of
SMSB3 using oligonucleotide-based site-directed mutagenesis. Equivalent SMSB4 mutations in the hinge region [F (T422P)] and RCL $[\mathrm{H}(\mathrm{S} 435 \mathrm{H})]$ were also introduced. The mutant molecules were expressed, purified and refolded as specified above for the wild type molecules.

\section{Complement Proteins}

C1, C1r, C1s, C2, C3, C3b, C4, C4b, C5, C6, C7, C8, C9, factor $\mathrm{B}$, factor $\mathrm{D}$, and properdin were purchased from Complement Technology (Tyler, USA). Human MBL was purchased from Statens Serum Institute (Copenhagen, Denmark). C1q [66] and factor I [67] were purified from human plasma as described previously.

\section{Localization of SMSs and Human IgG by Immunohistochemistry}

The production of antisera against scabies mite proteins, tissue preparation of human mite-infested skin samples and the immunolocalization of scabies mite proteins were accomplished as previously outlined [68]. Antibodies against purified recombinant SMSB3 and SMSB4 proteins were raised in C57BL/ 6 female mice. In order to confirm the specificity of the anti-sera against SMSB3 and SMSB4, purified SMS proteins were separated by SDS-PAGE and transferred onto an Immubilon-FL PVDF membrane (Millipore), blocked with Odyssey blocking buffer $(L I$ COR Biosciences) overnight at $4^{\circ} \mathrm{C}$, and incubated for $1 \mathrm{~h}$ with 1:500 dilutions of primary antibody raised against the recombinant SMS proteins. Membranes were washed four times in PBS, followed by incubation for $1 \mathrm{~h}$ with a fluorescent secondary antibody (Goat anti mouse-IR dye $\lambda_{800} \mathrm{~nm}$ ) at 1:10,000 dilution. Proteins were visualized using an Odyssey Infrared Imaging System (LI-COR Biosciences).

Tissue samples of scabies mite-infected human skin were formalin-fixed overnight, paraffin embedded and cut into $4 \mu \mathrm{m}$ serial sections. After deparaffinisation, the slides were washed with Milli Q water for 10 min followed by 15 min washes in PBS at $\mathrm{pH}$ 7.2. In order to reduce non-specific background staining, sections were blocked with casein (BACKGROUND Sniper, BioCare Medical) for $10 \mathrm{~min}$, followed by overnight incubation at $4^{\circ} \mathrm{C}$ with $10 \%(\mathrm{v} / \mathrm{v})$ goat serum in $1 \%(\mathrm{w} / \mathrm{v})$ BSA in PBS. Endogenous peroxidase activity was blocked with $3 \%(\mathrm{v} / \mathrm{v}) \mathrm{H}_{2} \mathrm{O}_{2}$ in blocking buffer. For the primary immunodetection of SMSB3 and SMSB4, the produced polyclonal mouse sera were incubated for $2 \mathrm{~h}$ at a dilution of 1:1000. Pre-bleeds from mice used for antibody production served as negative controls and were incubated on sections of the same series. Incubation with secondary anti-mouse-HRP antibodies (from DAKO EnVision system for SMSB4 and from BioCare Medical for SMSB3) was done for $40 \mathrm{~min}$ at room temperature. Anti-human IgG was used as a positive control to identify the mite gut on adjacent sections. These sections were incubated for $40 \mathrm{~min}$ at $4^{\circ} \mathrm{C}$ with an antihuman IgG-HRP polyclonal antibody (1:500; Sapphire Biosciences). All slides were washed in PBS and stained using the Vector NovaRed peroxidase substrate kit (Vector Laboratories). Counterstaining with hematoxylin was carried out as previously described. Slides were scanned using a Scan Scope XT microscope (Aperio Technologies) at $40 \times$ magnification.

\section{Enzyme Assays}

Enzyme assays were performed in standard assay buffer (100 mM Tris-HCl, pH $8.210 \mathrm{mM} \mathrm{CaCl}_{2}$ and $0.05 \%$ (v/v) PEG 8000) for serine proteases, with commercially available methylcoumarin substrates (Sigma Aldrich) at $37^{\circ} \mathrm{C}$ in a final 
volume of $100 \mu \mathrm{l}$ in 96-well plates. Enzyme assays with cysteine proteases were analyzed in $100 \mathrm{mM}$ potassium phosphate, $\mathrm{pH}$ 6.0, $2.5 \mathrm{mM}$ cysteine for Sar s 1c and $100 \mathrm{mM}$ sodium acetate-HCl, pH 5.5, 1.5 mM EDTA and $1 \mathrm{mM}$ dithiothreitol for cathepsin L. The house dust mite serine protease Der p 3 was kindly provided by Professor Wayne Thomas (Telethon Inst for Child Health Research, Perth, Australia) and the scabies mite cysteine protease Sar s 1c by Dr Masego Johnstone (QIMR, Brisbane, Australia). The recombinant human cathepsin L was kindly provided by Weiwen Dai (Monash University, Melbourne, Australia). Trypsin, Chymotrypsin, Elastase, Thrombin and Cathepsin L were purchased from Sigma Aldrich. Thrombin and cathepsin L were separately pre-incubated in their assay buffers at $37^{\circ} \mathrm{C}$ for $15 \mathrm{~min}$ before use. SMSs and active proteases were pre-incubated at $37^{\circ} \mathrm{C}$ for $10 \mathrm{~min}$ in the corresponding buffer, followed by addition of the substrate to start the enzyme reaction. Rates obtained in the absence of SMSs were defined as $100 \%$. Fluorescence was continuously measured on a POLARstar Optima fluorescent microtiter plate reader (BMG Labtech, Melbourne, Australia) at $30 \mathrm{~s}$ intervals at excitation and emission wavelengths of 370 and $460 \mathrm{~nm}$, respectively. Generally, the hydrolysis rate was recorded for 75 minutes and the linear part of the enzymatic reaction was taken to calculate the rates depending on the enzyme used.

SMS B3 was buffer exchanged into $100 \mathrm{mM}$ Tris, $\mathrm{pH} 8.2$, $10 \mathrm{mM} \mathrm{CaCl} 2$ and $100 \mu \mathrm{g} / \mathrm{ml}(10 \mu \mathrm{g}$ total $)$ of the serpin was incubated with $25 \mu \mathrm{g} / \mathrm{ml}(2.5 \mu \mathrm{g}$ total) human leukocyte (neutrophil) elastase (Sigma Aldrich) at $37^{\circ} \mathrm{C}$ for $15 \mathrm{~min}$. Subsequently, the reaction was inhibited by addition of the elastase-specific inhibitor $\mathcal{N}$-methoxysuccinyl-Ala-Ala-Pro-Val-chloromethyl ketone (Sigma Aldrich) to a $10 \mu \mathrm{M}$ final concentration and incubated at room temperature for $30 \mathrm{~min}$. Control reactions containing no elastase were incubated under the same conditions with or without addition of the inhibitor. Aliquots $(3 \mu \mathrm{g})$ of the produced samples were tested in duplicate assays for the deposition of complement component C9, as outlined below. Each experiment was independently repeated three times.

\section{Analysis of Protease/serpin Complexes}

In order to analyze serpin/protease complexes, serpins were further purified by additional size exclusion chromatography to remove putative serpin aggregates. Refolded and concentrated protein samples were applied at $4^{\circ} \mathrm{C}$ to a Superdex 75 column (HR 10/30) using an ÄKTA HPLC system (GE Healthcare) and a $500 \mu$ loop equilibrated with 4 column volumes of size exclusion buffer (50 mM Tris-HCl, pH 8.0, $150 \mathrm{mM} \mathrm{NaCl,} 50 \mathrm{mM}$ arginine and $1 \mathrm{mM}$ dithiothreitol). Proteins were eluted using 1.5 column volumes of size exclusion buffer at a flow rate of $0.5 \mathrm{ml} / \mathrm{min}$ with $0.5 \mathrm{ml}$ fractions being collected. Fractions containing the serpins were identified by SDS-PAGE in conjunction with an assay examining the inhibitory effects of fractions on chymotrypsin activity. Serpin/protease complexes were analyzed using SDS-PAGE under non-reducing conditions and Western blotting after pre-incubation of the serpin with each protease in serpin buffer at $37^{\circ} \mathrm{C}$ for $15 \mathrm{~min}$ at serpin/protease ratios of $4: 1$, followed by $1 \mathrm{~min}$ incubation at $95^{\circ} \mathrm{C}$ and the addition of SDSPAGE loading buffer.

For the formation of serpin/protease complexes between the purified, refolded SMSs and purified complement proteases $(\mathrm{C} 1 \mathrm{r}$, $\mathrm{C} 1 \mathrm{~s})$, the molecules were incubated for $1 \mathrm{~h}$ at $37^{\circ} \mathrm{C}$ in $\mathrm{GVB}^{2+}$ buffer ( $5 \mathrm{mM}$ veronal buffer, $\mathrm{pH}$ 7.35, $140 \mathrm{mM} \mathrm{NaCl}, 0.1 \%$ (w/v) gelatin, $1 \mathrm{mM} \mathrm{MgCl}_{2}, 0.15 \mathrm{mM} \mathrm{CaCl}$ ) at serpin/protease ratios of $3: 1$ and boiled in non-reducing loading buffer at $95^{\circ} \mathrm{C}$. The samples were separated by gradient SDS-PAGE (4-12\%), trans- ferred onto an Immubilon-FL PVDF membrane (Millipore), blocked with Odyssey blocking buffer (LI-COR Biosciences) overnight at $4^{\circ} \mathrm{C}$, and incubated for $1 \mathrm{~h}$ with 1:2000 dilutions of primary antibody raised against the recombinant SMS proteins. Immunodetection was performed using fluorescent secondary antibody (Goat anti mouse-IR dye $\lambda_{800} \mathrm{~nm}$ ) at a dilution of $1: 15000$, followed by coomassie staining. Proteins were visualized using an Odyssey Infrared Imaging System (LI-COR Biosciences).

\section{Hemolytic Assays}

To assess the activity of the classical pathway of complement, sheep erythrocytes (Swedish National Veterinary Institute) were washed three times using cold $\mathrm{DGVB}^{2+}$ buffer $(2.5 \mathrm{mM}$ veronal buffer, pH 7.35, $70 \mathrm{mM} \mathrm{NaCl}, 140 \mathrm{mM}$ glucose, $0.1 \%(\mathrm{w} / \mathrm{v})$

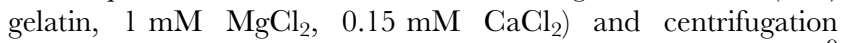
$\left(950 \times \mathrm{g}, 4^{\circ} \mathrm{C}, 4 \mathrm{~min}\right)$, resuspended to a concentration of $10^{9}$ cells $/ \mathrm{ml}$ and incubated, with gentle shaking, for $20 \mathrm{~min}$ at $37^{\circ} \mathrm{C}$, with an equal volume of sensitizing antibodies (amboceptor, Dade Behring) diluted 1:3000 in $\mathrm{DGVB}^{2+}$ buffer [10]. After two washes with $\mathrm{DGVB}^{2+}$ at $4{ }^{\circ} \mathrm{C}, 8 \times 10^{7}$ cells $/ \mathrm{ml}$ were incubated for $1 \mathrm{~h}$ at $37^{\circ} \mathrm{C}$ with $0.125 \%$ normal human serum (NHS) in $\mathrm{DGVB}^{2+}$ buffer, in a total volume of $150 \mu \mathrm{l}$ in 96-well plates under continuous shaking. Before incubation with erythrocytes, NHS was pre-incubated with various concentrations of SMSs or BSA, as a negative control, for $10 \mathrm{~min}$ at $37^{\circ} \mathrm{C}$. NHS was prepared from blood of six to nine healthy volunteers after informed consent and following review by the local ethical board at Lund University or the Queensland Institute of Medical Research, respectively. Residual erythrocytes were separated by centrifugation $(950 \times \mathrm{g}$, $\left.4^{\circ} \mathrm{C}, 3 \mathrm{~min}\right)$ and the hemolytic activity, i.e. the amount of lysed erythrocytes, was determined by spectrophotometric measurement of the amount of released hemoglobin $(\lambda=405 \mathrm{~nm})$. The lysis obtained in the absence of SMSs was defined as $100 \%$ hemolytic activity.

To assess the activity of the alternative pathway, rabbit erythrocytes (HeamoView Diagnostics, Pullenvale, Qld, Australia) were washed three times with $\mathrm{Mg}^{2+}$ EGTA buffer $(2.5 \mathrm{mM}$ veronal buffer ( $\mathrm{pH} \mathrm{7.3)}$ containing $70 \mathrm{mM} \mathrm{NaCl}, 140 \mathrm{mM}$

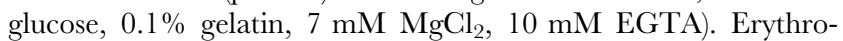
cytes at a concentration of $6 \times 10^{7}$ cells $/ \mathrm{ml}$ were incubated for $1 \mathrm{~h}$ at $37^{\circ} \mathrm{C}$ with $1.6 \%$ NHS diluted in $\mathrm{Mg}^{2+}$ EGTA buffer in a total volume of $150 \mu \mathrm{l}$. Before incubation with erythrocytes, NHS was preincubated with various concentrations of SMSs or BSA, as a negative control, for $10 \mathrm{~min}$ at $37^{\circ}$. Residual erythrocytes were separated by centrifugation $\left(950 \times \mathrm{g}\right.$ at $4^{\circ} \mathrm{C}$ for $\left.3 \mathrm{~min}\right)$ and the hemolytic activity was determined spectrophotometrically as described above. The lysis obtained in the absence of SMSs was defined as $100 \%$ hemolytic activity.

\section{Complement Deposition Assays}

Unless stated otherwise, all incubation steps were performed at room temperature, in a total volume of $50 \mu \mathrm{l}$, followed by extensive washing with $50 \mathrm{mM}$ Tris- $\mathrm{HCl}, \mathrm{pH} 8.0,150 \mathrm{mM} \mathrm{NaCl}$ and $0.1 \%(\mathrm{v} / \mathrm{v})$ Tween 20. Microtiter plates (96-well; Maxisorp, Nunc) were incubated overnight at $4^{\circ} \mathrm{C}$ with $50 \mathrm{mM}$ sodium carbonate, pH 9.6 containing the following components: for the classical pathway, $2.5 \mu \mathrm{g} / \mathrm{ml}$ aggregated human IgG (Immuno); for the lectin pathway, $100 \mu \mathrm{g} / \mathrm{ml}$ mannan (Sigma-Aldrich); and for the alternative pathway, $20 \mu \mathrm{g} / \mathrm{ml}$ zymosan (Sigma-Aldrich). Coating with $1 \%(\mathrm{w} / \mathrm{v})$ BSA was used as negative control. The wells were blocked with $250 \mu \mathrm{l}$ of blocking solution ( $1 \%$ (w/v) BSA in PBS) for $2 \mathrm{~h}$. To analyze the classical and lectin pathways, $1 \%$ and $2 \%$ NHS, respectively, were incubated in $\mathrm{GVB}^{2+}$ buffer (5 mM veronal buffer, $\mathrm{pH} 7.35,140 \mathrm{mM} \mathrm{NaCl}, 0.1 \%$ (w/v) 
gelatin, $1 \mathrm{mM} \mathrm{MgCl} 2,0.15 \mathrm{mM} \mathrm{CaCl}_{2}$ ) for $20 \mathrm{~min}$ (for detection of the complement proteins $\mathrm{C} 4 \mathrm{~b}$ and $\mathrm{C} 3 \mathrm{~b}$ ) or $60 \mathrm{~min}$ (for detection of $\mathrm{Clq}, \mathrm{MBL}$ and $\mathrm{C} 9$ ) at $37^{\circ} \mathrm{C}$. For the alternative pathway, $4 \%$ $(\mathrm{v} / \mathrm{v})$ NHS was incubated in $\mathrm{Mg}^{2+}$ EGTA buffer $(2.1 \mathrm{mM}$ veronal buffer, pH 7.35, $60 \mathrm{mM} \mathrm{NaCl}, 120 \mathrm{mM}$ glucose, $0.1 \%$ (w/v) gelatin, $7 \mathrm{mM} \mathrm{MgCl}$, $10 \mathrm{mM}$ EGTA) for $35 \mathrm{~min}$ for detection of $\mathrm{C} 3 \mathrm{~b}$ or for $1 \mathrm{~h}$ for detection of C9. Serum concentrations were chosen on the basis of initial titrations and represent conditions under which each assay is most sensitive to changes. The alternative pathway is known to require higher concentrations of serum to function properly. NHS was pre-incubated for $10 \mathrm{~min}$ at $37^{\circ} \mathrm{C}$ with various concentrations of SMSs or BSA, as a negative control, before addition to the microtiter plate. Complement activation was assessed by detection of deposited complement proteins using rabbit polyclonal antibodies against $\mathrm{Clq}, \mathrm{C} 4 \mathrm{c}$, and C3d (Dako), or goat polyclonal antibodies against MBL (R\&D Systems) and C9 (Complement Technology) diluted in blocking solution. After $1 \mathrm{~h}$ incubation with the primary antibody, HRPconjugated secondary antibodies against rabbit or goat IgG (Dako) were diluted in blocking solution and added for $30 \mathrm{~min}$ (for C4b and C3b detection) or $60 \mathrm{~min}$ (for C1q, MBL, C9). Bound enzyme was detected using o-1,2-phenylenediamine dihydrochloride tablets (OPD, Dako) in presence of hydrogen peroxide and the absorbance was measured at a wavelength of $490 \mathrm{~nm}$. The absorbance obtained in the absence of SMSs was defined as $100 \%$.

\section{Direct Binding Assays}

Unless stated otherwise, all incubation steps were performed in a total volume of $50 \mu \mathrm{l}$, followed by extensive washing, as described for the complement activation assays. Various purified complement proteins were coated onto microtiter plates as described above at a concentration of $10 \mu \mathrm{g} / \mathrm{ml} 1 \%$ (w/v) BSA was used as a negative control. The wells were blocked with $250 \mu \mathrm{l}$ of blocking solution and incubated at room temperature for $2 \mathrm{~h}$. SMS proteins $(5-20 \mu \mathrm{g} / \mathrm{ml})$ were diluted in binding buffer $(50 \mathrm{mM}$ HEPES, $\mathrm{pH} 7.4,100 \mathrm{mM} \mathrm{NaCl}, 2 \mathrm{mM} \mathrm{CaCl} 2$ ) and allowed to bind for $4 \mathrm{~h}$ at $4^{\circ} \mathrm{C}$. Specific mouse polyclonal antibodies against SMSs were then added to the wells, followed by an HRPconjugated goat anti-mouse IgG antibody (Dako). All antibodies were diluted in blocking buffer at a ratio of 1:4000 for SMSs and 1:2000 for HRP-IgG and incubated at room temperature for $1 \mathrm{~h}$. Bound HRP was detected as described above.

For NHS binding assays, microtiter plates were coated with $10 \mu \mathrm{g} / \mathrm{ml}$ recombinant purified SMSB3, SMSB4 and BSA as negative control in $50 \mathrm{mM}$ sodium carbonate, $\mathrm{pH} 9.6$ at $4^{\circ} \mathrm{C}$ over night. Coating with $1 \%(\mathrm{v} / \mathrm{v})$ NHS was used as positive control. ELISA conditions were optimized for specific binding of the antibodies against individual complement proteins. After blocking as described above, wells were incubated with serial dilutions of NHS $(0-100 \%)$ for $10,20,40$ or $60 \mathrm{~min}$ at $37^{\circ} \mathrm{C}$. Bound complement proteins were detected by incubation with primary antibodies against human complement factors for $1 \mathrm{~h}$ at room temperature (for immunodetection of $\mathrm{C} 1 \mathrm{r}, \mathrm{MBL}, \mathrm{C} 2$, factor $\mathrm{B}$, factor D and C8 at a dilution of 1:1000; for detection of C1s at 1:2500; for detection of C1q, C3d, C4c, C6 and properdin at 1:4000). To further confirm that complement serine proteases were not interfering with the ELISA, i.e. digesting the antibodies, assays for the detection of the heat-sensitive proteins factor $\mathrm{B}$ and C2 were additionally performed with and without heat-inactivation $\left(15 \mathrm{~min}\right.$ at $56^{\circ} \mathrm{C}$ ) after NHS binding. Depending on antibody specificity and signal intensity, rabbit anti-goat/HRP and goat anti-rabbit/HRP secondary antibodies were applied for $30 \mathrm{~min}$ or $1 \mathrm{~h}$ (at dilutions of 1:1000-1:5000) in blocking buffer. Bound HRP was detected at $490 \mathrm{~nm}$ as described above.

\section{Statistical Analysis}

All experiments were carried out at least three times in duplicate, unless stated otherwise. Statistical significance was determined using one-way ANOVA (Origin 5.0 Professional software). Values of $p<0.05$ were considered significant.

\section{Ethics Statement}

All animals were handled in strict accordance with good animal practice as defined by the Australian code of practice for the care and use of animals for scientific purposes, and the National Health \& Medical Research Council's (NHMRG) Animal Code of Practice. The Queensland Institute of Medical Research Animal Ethics Committee approved the production of polyclonal antibodies in mice for this study, in compliance with the Code of practice, the NHMRC, and the Queensland government responsible authority. Written informed consent was obtained from the crusted scabies patient for the collection of shed skin crusts. The protocol was approved by the Human Research Ethics Committee of the Northern Territory Department of Health and Families and the Menzies School of Health Research.

\section{Results}

Sequence Analysis and Recombinant Expression of SMSs

Two novel cDNA sequences coding for the scabies mite serpins SMSB3 and SMSB4 were amplified by PCR from scabies mite cDNA libraries. The corresponding full-length amino acid sequences consisted of 427 and 498 residues, respectively, and had predicted signal sequences indicating that they are secretory proteins. The theoretical molecular masses and isoelectric points were $46.5 \mathrm{kDa}$ and 5.61 for SMSB3 and $53.6 \mathrm{kDa}$ and 5.92 for SMSB4, respectively. Both SMSs showed sequence similarities to human clade B serpins and to serpins from other arthropods such as ticks, lice and house dust mites (47-62\%). Both scabies mite sequences revealed the typical domains and highly conserved residues of the serpin superfamily. SMSB4 contained an additional 103 amino acid residue long N-terminal elongation, which is different from human homologues and other mammalian serpins. In order to analyze the inhibitory mechanism of the scabies mite serpins, six mutants were created introducing point mutations within the RCL hinge or RCL variable regions (Fig. 1A).

All proteins investigated in this study were expressed in E. coli with N-terminal hexaHis-tags and purified from thoroughly washed inclusion bodies under denaturing conditions by affinity chromatography. Subsequent refolding in presence of L-arginine and dithiothreitol yielded an average of $6 \mathrm{mg}$ SMSB3 and $160 \mu \mathrm{g}$ SMSB4 per liter of induced culture, i.e. $20-30 \%$ of the purified proteins were refolded into soluble proteins. The purified proteins exhibited the expected molecular masses of 47 and $54 \mathrm{kDa}$, respectively (Fig. 1B). The six mutated serpins were successfully produced following the same procedure and showed identical molecular masses and purity compared to the corresponding wild type SMSs on SDS-PAGE (data not shown).

\section{SMSs are Localized in the Mite Digestive System and Excreted into the Epidermis}

The specificity of the anti-sera raised against SMSB3 and SMSB4 was confirmed by Western analysis (Fig. 2). The presence of both SMSs in the scabies mite gut was demonstrated by probing serial sections of human mite-infested skin with SMS-specific antibodies in comparison to staining with human $\operatorname{IgG}$, which for the purpose of this experiment served as a positive control for gut localization (Fig. 3). Human IgG was localized to the gut (Fig. 3, section 4 and 8) as previously documented $[9,68]$. This confirmed 


\begin{tabular}{|c|c|c|c|c|c|c|c|c|c|c|c|c|c|c|c|c|c|c|c|c|c|c|}
\hline \multirow[b]{2}{*}{ Serpin } & \multicolumn{9}{|c|}{ RCL hinge } & \multicolumn{13}{|c|}{$\mathrm{RCL}$ variable } \\
\hline & P17 & 16 & 15 & 14 & 13 & 12 & 11 & 10 & 9 & 8 & 7 & 6 & 5 & 4 & 3 & 2 & 1 & $1 '$ & $2^{\prime}$ & 3 ' & $4^{\prime}$ & $5^{\prime}$ \\
\hline \multirow{5}{*}{$\begin{array}{l}\text { SMSB3 wild type } \\
\text { SMSB3/A } \\
\text { SMSB3/B } \\
\text { SMSB3/C } \\
\text { SMSB3/D }\end{array}$} & $\mathrm{E}$ & $E$ & G & $\mathrm{T}$ & $E$ & A & $A$ & $A$ & G & $\mathrm{T}$ & $Y$ & 1 & A & A & V & $\mathrm{F}$ & G & $\mathrm{L}$ & $A$ & $\mathrm{~L}$ & G & D \\
\hline & . & . & . & $E$ & . & . & . & V & . & . & . & . & . & . & . & . & . & . & . & . & . & . \\
\hline & . & . & . & $\mathrm{P}$ & . & . & . & . & . & . & . & . & . & . & . & . & 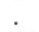 & . & $\cdot$ & 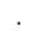 & . & \\
\hline & . & . & . & . & . & . & . & . & . & . & . & . & . & . & . & . & $\mathrm{H}$ & . & . & . & $\cdot$ & . \\
\hline & . & . & . & . & . & . & . & . & . & . & . & . & . & . & . & . & . & $\mathrm{P}$ & . & . & . & . \\
\hline \multirow{3}{*}{$\begin{array}{l}\text { SMSB4 wild type } \\
\text { SMSB4/F } \\
\text { SMSB4/H }\end{array}$} & $E$ & $E$ & G & $\mathrm{T}$ & $E$ & A & $A$ & A & A & $T$ & A & V & 1 & $\mathrm{~F}$ & A & $\mathrm{R}$ & $S$ & G & $\mathrm{R}$ & $\mathrm{P}$ & A & $F$ \\
\hline & . & . & . & $\mathrm{P}$ & . & . & . & . & . & . & . & . & . & . & . & & . & . & . & . & . & . \\
\hline & . & . & . & . & . & . & . & . & . & . & . & . & . & . & . & $P$ & . &. & . & . & . & . \\
\hline
\end{tabular}

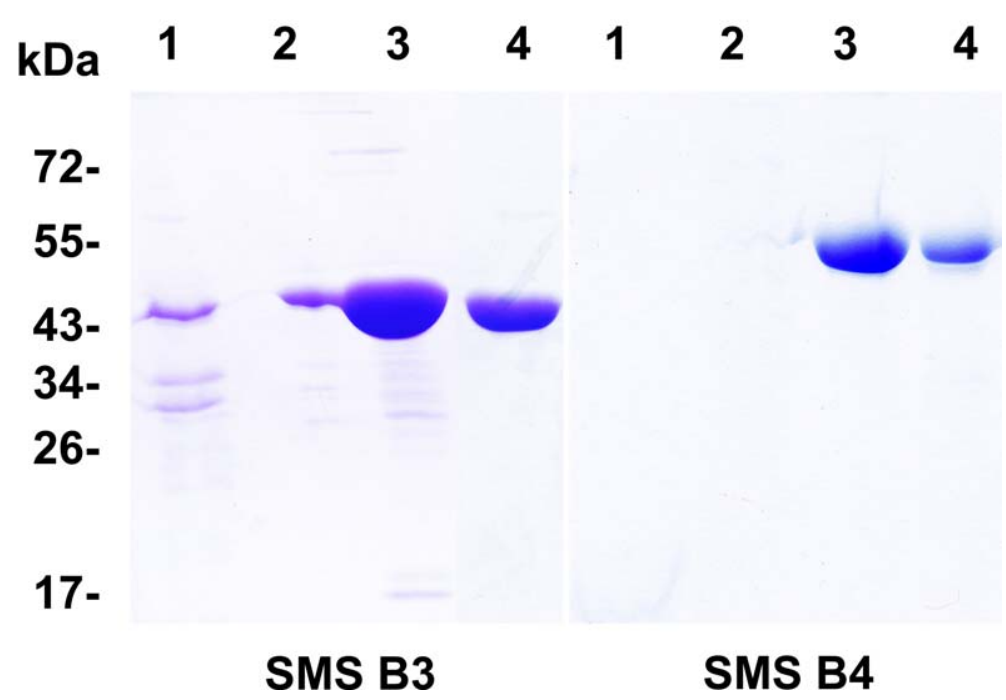

Figure 1. Sequence details and recombinant expression of SMSs and mutants. (A) Shown are the sequence changes in the SMS mutants compared to wild type sequences. Numbering scheme according to [82]. Point mutations were introduced in the two segments of the RCL domain: i) the distal (P9-P5') variable region that resembles the protease substrate and is attacked by a target protease, and ii) the proximal (P15-P9) hinge region that is well conserved and inserts into $\beta$-sheet A during inactivation of a protease in inhibitory serpins. (B) Purification and refolding of SMSB3 and SMSB4. Shown are immobilized nickel affinity chromatography fractions after separation by SDS-PAGE and Coomassie staining. Both SMSs revealed the expected bands of $47 \mathrm{kDa}$ and $54 \mathrm{kDa}$, respectively. 1, loaded sample; 2, wash; 3, elution with $250 \mathrm{mM}$ imidazole, 4, active serpin after refolding.

doi:10.1371/journal.pone.0040489.g001

that, in the adjacent serial section (Fig. 3, section 3 and 7), labelling by anti-serpin Abs was indeed in the gut. The polyclonal antibody sera used for the immunolocalization studies were raised in mice against $E$. coli-derived SMSB3 and SMSB4 and reacted specifically with each protein in western blot analysis (Fig. 2). In addition to their location in the digestive tract of the mite, the SMSs were localized to external acellular masses, known as fecal pellets. This is exemplarily shown for SMSB3 (Fig. 3, section 11). In all cases, the sections probed with the pre-immune serum as negative control only stained with the counterstain, clearly excluding any unwanted background staining (Fig. 3, sections 2, 6 and 10). From these results we conclude that both SMSs are located to the digestive tract of the scabies mite and are excreted into the epidermis with the feces of the parasite. Consequently, the serpins are highly likely to be involved in functions within the gut of the mite, but equally may interact with host proteins present in the epidermis after excretion in the feces.

\section{SMSs Inhibit Mammalian Proteases and Form Serpin/ protease Complexes}

Enzyme activity assays in the presence and absence of both wild type SMSs revealed that SMSB3 and SMSB4 are active and

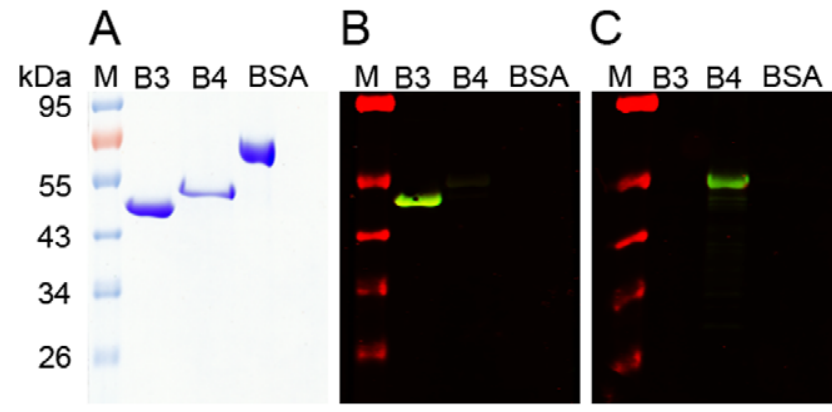

Figure 2. Specificity of mouse antisera raised against recombinant SMSB3 and SMSB4. The purified SMS proteins and BSA (used as a non-related control) were electrophoresed on SDS-PAGE and stained with Coomassie blue R-250 (A) and then immunoblotted with the anti-sera raised against SMSB3 (B) and SMSB4 (C), confirming the specificity of the antibodies and lack of cross-reaction with BSA. doi:10.1371/journal.pone.0040489.g002

preferentially inhibit mammalian serine proteases, such as trypsin, chymotrypsin and human leukocyte elastase (Fig. 4A). In contrast, the scabies mite serine protease Sar s 3, its house dust mite 

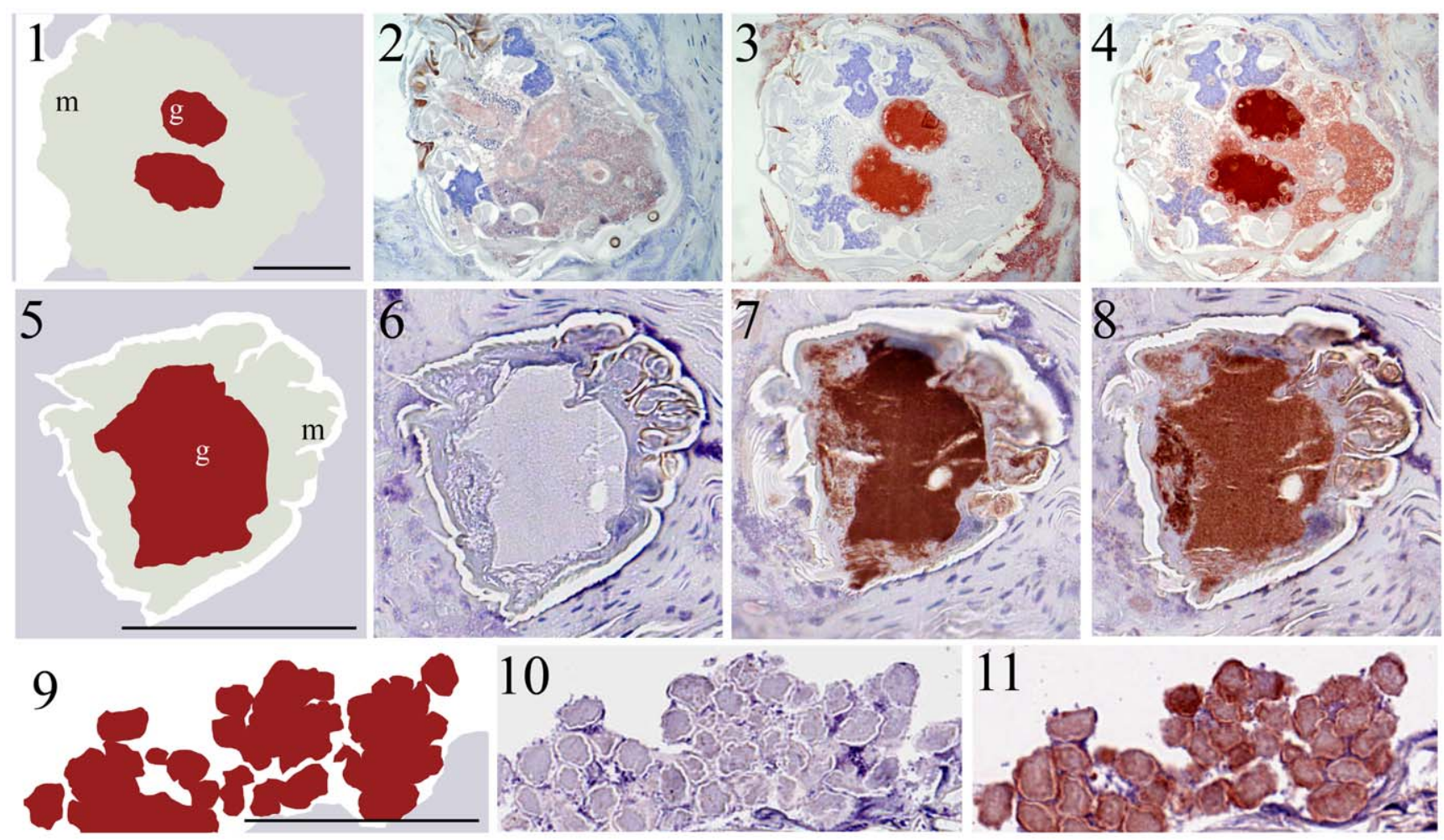

Figure 3. Immunolocalization of SMSs and IgG in scabies mite-infested human skin. Schematic diagrams $\mathbf{1}$ and $\mathbf{5}$ outline the features visible in serial histological sections through a scabies mite in infested human skin. Red staining indicates binding of antibody to protein. Section $\mathbf{2}$ and $\mathbf{6}$ probed with pre-immune mouse serum as a negative control remained unstained, while equivalent regions were detected in section $\mathbf{4}$ and $\mathbf{8}$ when probed with anti-human IgG, a marker for mite gut [9], and in section $\mathbf{3}$ and $\mathbf{7}$ when probed with antibodies against SMSB4 and SMSB3, respectively. Schematic diagrams outline the features visible in serial histological sections through human epidermis containing scabies mite feces 9. Section $\mathbf{1 0}$ probed with pre-immune mouse serum as a negative control remained unstained, while equivalent regions were detected in section $\mathbf{1 1}$ when probed with anti-SMSB3 and in section 12 with anti-IgG. Staining of feces was also seen in equivalent experiments performed with antibodies against SMSB4 (not shown). Immunohistological co-localization of SMSs and host IgG indicated that both serpins are localized in the mite gut and mite feces within the burrows. b, burrow; f, feces; $g$, gut; $m$, mite. Scale bars (100 $\mu \mathrm{M})$ indicate the magnification level.

doi:10.1371/journal.pone.0040489.g003

homolog Der p 3 and the cysteine proteases Sar s 1c and human cathepsin L were not inhibited by either SMS. Values for the stoichiometry of inhibition (SI) of the three mammalian proteases by SMSB3 (Fig. 4B) were elucidated using linear regression to determine the inhibitor/enzyme ratio $\left([]_{0} /[\mathrm{E}]_{0}\right)$ resulting in the complete inhibition of the enzyme. While trypsin and elastase inhibition by SMSB3 and SMSB4 were inefficient, the SI value calculated for SMSB3 inhibition of chymotrypsin was 12.9, indicating that this serpin inhibited chymotrypsin-like proteases most effectively.

Serpin/protease complexes formed by the classical mechanism involving RCL cleavage and formation of an acyl-enzyme intermediate are heat and SDS-stable and hence can be visualized after SDS-PAGE. Such analysis of SMSB3/protease complexes confirmed that the inhibition of chymotrypsin was due to the formation of a covalent bond between the enzyme and the inhibitor (Fig. 4G). In contrast, the slight inhibition of trypsin and elastase activity in presence of SMSB3 apparently occurred due to the serpin acting as an alternative substrate for the enzymes, based on the degradation products visible on SDS-PAGE analysis. Scabies mite serine protease Sar s 3 did not affect the scabies mite serpin (Fig. 4C). Western blotting of the SDS-PAGE gels after complex formation and immunodetection with antibodies against SMSB3 confirmed that the high molecular mass complex band formed contained SMSB3 (data not shown).
SMSB3/A and SMSB3/B showed strongly impaired inhibitory activity against chymotrypsin in comparison with the wild type serpin (Fig. 4D). These mutants contain point mutations at P14 in the RCL-associated hinge region of SMSB3 (Fig. 1A), indicating that this region, which is integral to the conformational change occurring during the serpin mechanism, was indeed involved in the inhibition of this protease.

\section{SMSsB3 and SMSB4 do not Inhibit Blood Coagulation}

We tested the functionality of the intrinsic and the extrinsic coagulation pathways, involving multiple serine proteases, in the presence of the two recombinant mite serine protease inhibitors SMSB3 and SMSB4. Two standardized tests, the Activated Partial Thromboplastin Time (APTT) and the Prothrombin Time (PT) were assessed. Both SMSs had no effect on either pathway when tested at concentrations of 10,100 and $200 \mu \mathrm{g} / \mathrm{ml}(215 \mathrm{nM}$, $2.1 \mu \mathrm{M}$ and $4.2 \mu \mathrm{M}$ for SMSB3 and $186 \mathrm{nM}, 1.8 \mu \mathrm{M}$ and $3.6 \mu \mathrm{M}$ for SMSB4) (Fig. S1).

\section{SMSs inhibit the hemolytic activity of human serum}

A detailed functional analysis was performed to investigate the anti-complement properties of the scabies mite serpins. Both SMSs inhibited human complement in a hemolytic assay measuring the activation of the classical pathway, while the six mutants (Fig. 1A) showed distinct changes in inhibition (Fig. 5). SMSB3 and SMSB4 
A

\begin{tabular}{|c|c|c|c|c|c|c|}
\hline Protease & Source & $\begin{array}{l}\text { Conc. } \\
\text { (nM) }\end{array}$ & $\begin{array}{c}\text { Ratio } \\
\text { I/E }\end{array}$ & $\begin{array}{c}\text { Substrate } \\
\text { (concentration) }\end{array}$ & \multicolumn{2}{|c|}{$\%$ Inhibition } \\
\hline \multicolumn{7}{|l|}{ Serine proteases } \\
\hline Trypsin & bovine & 0.5 & 100 & Z-GGR-AMC HCl $(5 \mu \mathrm{M})$ & $16.0 \pm 0.7$ & $\begin{array}{l}6.3 \pm \\
1.1\end{array}$ \\
\hline Chymotrypsin & bovine & 0.5 & 100 & $\begin{array}{l}\text { N-Succinyl-AAPF- } \\
\text { AMC }(5 \mu \mathrm{M})\end{array}$ & $100 \pm 0$ & $\begin{array}{c}22.8 \pm \\
1.3\end{array}$ \\
\hline Elastase & human & 2.2 & 20 & Z-APA-AMC HCl (5 $\mu \mathrm{M})$ & $3.9 \pm 0.7$ & $\begin{array}{l}6.3 \pm \\
3.5\end{array}$ \\
\hline Thrombin & human & 20 & $\leq 100$ & Z-GPR-AMC HCl $(10 \mu \mathrm{M})$ & 0 & 0 \\
\hline Der p 3 & house dust mite & 0.5 & $\leq 120$ & Z-GGR-AMC $\mathrm{HCl}(100 \mu \mathrm{M})$ & 0 & 0 \\
\hline Sar s 3 & scabies mite & 0.5 & $\leq 100$ & Z-GGR-AMC $\mathrm{HCl}(50 \mu \mathrm{M})$ & 0 & 0 \\
\hline \multicolumn{7}{|l|}{ Cysteine proteases } \\
\hline Cathepsin L & human & 1.0 & $\leq 100$ & Z-FR-AMC HCl $(100 \mu \mathrm{M})$ & 0 & 0 \\
\hline Sar s 1c & scabies mite & 30 & $\leq 100$ & $\begin{array}{l}\text { Boc-QAR-AMC HCl } \\
(100 \mu M)\end{array}$ & 0 & 0 \\
\hline
\end{tabular}
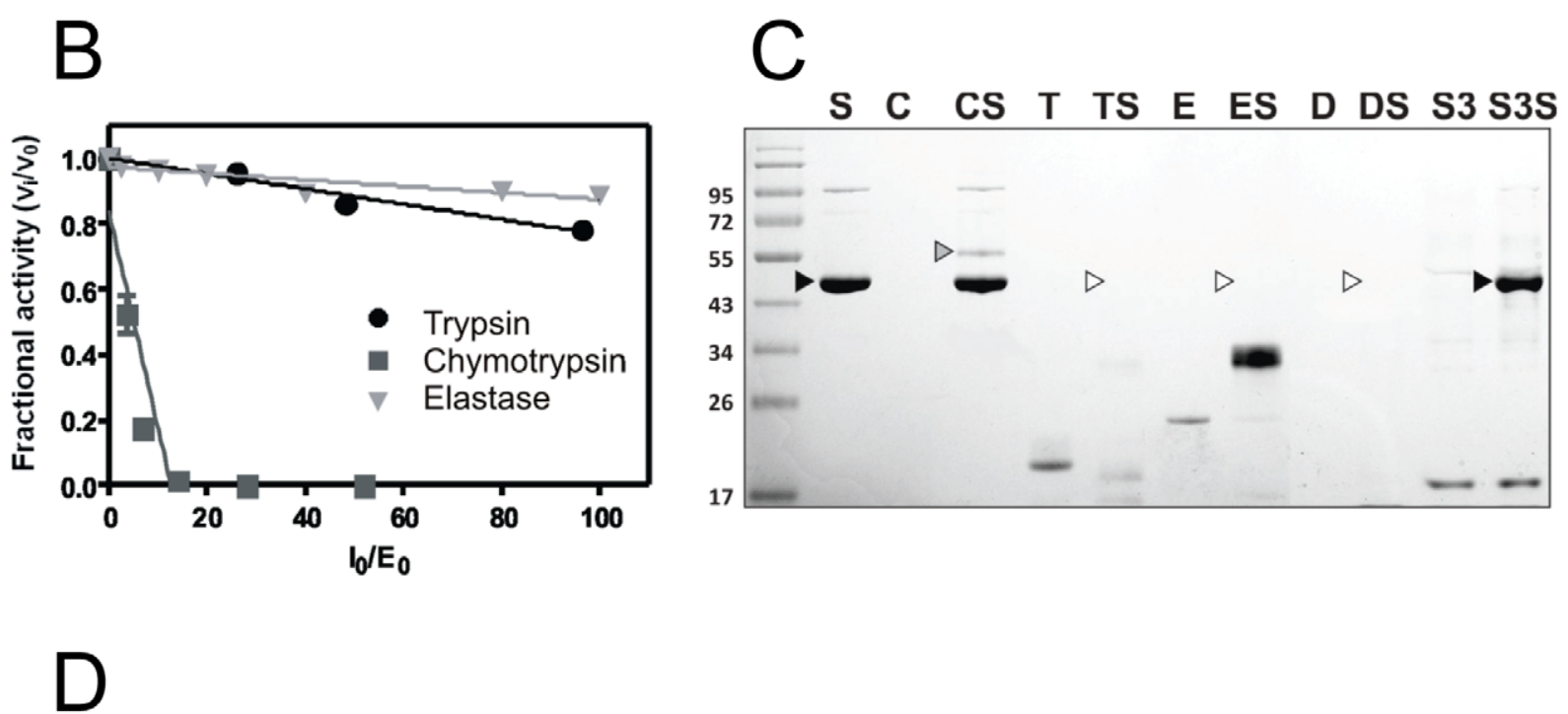

Table III: Inhibition of chymotrypsin activity by SMSB3 and its hinge mutants.

\begin{tabular}{lcc}
\hline & Mutation & SI value \\
\hline SMSB3 & wildtype & 12.9 \\
SMSB3/A & hinge & 150.1 \\
SMSB3/B & hinge & 108.0 \\
\hline
\end{tabular}

Figure 4. SMSs inhibit mammalian proteases and form serpin/protease complexes. (A) Inhibitory profile of mammalian and mite proteases by wild type SMSs (overview). Proteases were pre-incubated with different concentrations of SMSB3 or SMSB4 at $37^{\circ} \mathrm{C}$ for 10 min in the appropriate reaction buffer. The reaction was started by addition of the corresponding fluorescent aminomethyl-coumarin substrate and enzyme inhibition was measured as change in fluorescence in comparison with controls. Shown are means $\pm S D(n=3)$. (B) Stoichiometry of inhibition for SMSB3. The inhibitory activity was assessed by measuring residual enzyme activities of trypsin, chymotrypsin and leucocyte elastase. Enzymes were incubated with a 2-120:1 molar excess of SMSB3 at $37^{\circ} \mathrm{C}$ for $10 \mathrm{~min}$ in the appropriate reaction buffer. Residual enzyme activity was measured in triplicate ( $\mathrm{SD} \leq 5 \%$ ) by adding the appropriate aminomethyl-coumarin peptide substrate and determining the reaction velocity as change in fluorescence. The fractional activity was the ratio of the velocity of inhibited enzyme $\left(v_{i}\right)$ over the velocity of uninhibited control $\left(v_{o}\right)$. The initial inhibitor/enzyme ratios $\left(\left[\left[_{0}\right] /\left[E_{0}\right]\right)\right.$ represent the molar excess of serpin over enzyme. $(\mathbf{C})$ Complex formation between SMSB3 and serine proteases. Serpin/protease complexes were analyzed by SDS-PAGE under non-reducing conditions after pre-incubation of SMSB3 (black arrow) with each protease at $37^{\circ} \mathrm{C}$ for $15 \mathrm{~min}$ at serpin/protease ratios of 4:1. Covalent complex formation was found with chymotrypsin (grey arrow), while SMSB3 was 
degraded by trypsin, elastase and Der p 3 (white arrows). C, chymotrypsin; D, house dust mite Der p 3; E, neutrophil elastase; S, SMSB3; S3, scabies mite Sar s 3; T, trypsin. (D) Effects of SMSB3 and two mutants on chymotrypsin activity.

doi:10.1371/journal.pone.0040489.g004

reached total inhibition of complement-mediated lysis of sheep erythrocytes at protein concentrations of $40 \mu \mathrm{g} / \mathrm{ml}(860 \mathrm{nM})$ and $5 \mu \mathrm{g} / \mathrm{ml}(93 \mathrm{nM})$, respectively.

While SMSB3/A, a molecule containing a double point mutation in the hinge region (Fig. 1A), was as efficient as wild type SMSB3 in its ability to inhibit complement, the mutants SMSB3/C, SMSB3/D and SMSB3/B were significantly impaired in their ability to inhibit the classical pathway (Fig. 5A). The unchanged activity of SMSB3/A in comparison with the wild type serpin revealed that the hinge region required for the serpin inhibitory mechanism is not important for the inhibition of human complement by SMSB3, in contrast to the inhibition of chymotrypsin. The serpins containing proline mutations in the RCL or hinge region (SMSB3/D and SMSB3/B) required 4-fold and 5-fold higher protein concentrations, respectively, to cause $50 \%$ inhibition of the hemolytic activity in comparison with the wild type serpin (Fig. 5A). Similarly, 50\% inhibition was reached using 7 and 8-fold higher protein concentrations of the SMSB4 RCL and hinge mutants in comparison to wild type SMSB4 (Fig. 5B).

Experiments addressing the alternative pathway in hemolytic assays showed $40 \%$ inhibition in the presence of $100 \mu \mathrm{g} / \mathrm{ml}$ of wild

A

B
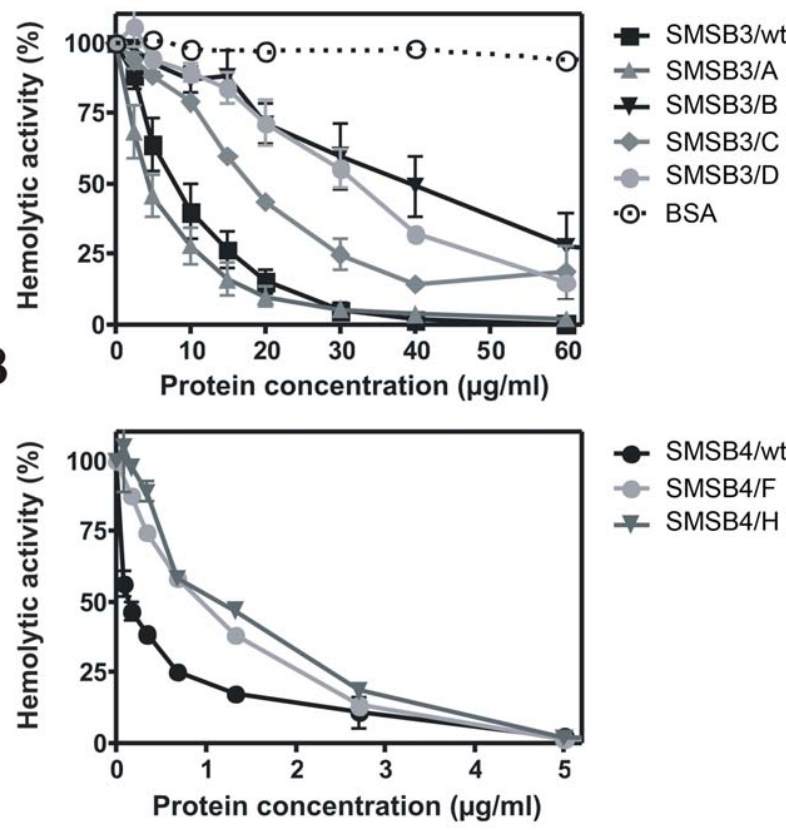

Figure 5. SMSs inhibit the hemolytic activity of human serum. Sheep erythrocytes opsonized with antibodies were incubated with $0.125 \%$ NHS to visualize the activity of the classical pathway of the human complement system. Serum was pre-incubated for $10 \mathrm{~min}$ at $37^{\circ} \mathrm{C}$ with various concentrations $(2.5-60 \mu \mathrm{g} / \mathrm{ml}$, i.e. $54-1300 \mathrm{nM})$ of SMSB3 and its four mutants (A), SMSB4 and its two mutants $(0.1-5 \mu \mathrm{g} /$ $\mathrm{ml}$, i.e. 2-93 nM) (B) and BSA as a negative control. After $1 \mathrm{~h}$ of incubation of NHS with erythrocytes at $37^{\circ} \mathrm{C}$, the degree of complement-mediated lysis was estimated by measurement of released hemoglobin. The lysis obtained in the absence of SMSs was defined as $100 \%$ hemolytic activity. An average of three independent experiments performed in duplicate is presented with bars indicating SEM. doi:10.1371/journal.pone.0040489.g005 type SMSB3, compared to no inhibition in the BSA control (data not shown).

\section{SMSs Inhibit All Three Complement Pathways}

Further analysis characterizing the deposition of human complement factors at different levels within the three activated complement pathways, revealed that SMSB3 and SMSB4 inhibited all three pathways by interfering with several steps of the cascades (Fig. 6). In an ELISA-based functional assay, aggregated $\mathrm{IgG}$, mannan or zymosan were used as activators of the classical, lectin and alternative pathways, respectively, leading to the deposition of the pathway-specific complement factors. After addition of human serum, pre-incubated with SMSs, changes in the deposition of complement proteins were detected using antibodies specific to individual complement components, allowing assessment of the level at which inhibition of the complement pathway occurred.

SMSB4 inhibited at the Glq level, and stronger inhibition was seen at the C4b and C9 levels, as indicated by the significantly lower serpin concentrations needed to reach $50 \%$ inhibition of the classical pathway (Fig. 6). In the lectin pathway the presence of SMSB4 resulted in a significant decrease in the deposition of MBL, and a significantly greater decrease in the deposition of C4b, C3b and C9 (Fig. 6). Strong inhibition occurred at the C3b level in the alternative pathway (Fig. 6), but no significant change in complement inhibition was found in the terminal pathway (C9). In contrast, SMSB3 exerted its strongest inhibition at the C9 level of all three complement pathways, and only weak inhibition at the level of C3b in the lectin pathway. Higher concentrations of both SMSs were needed to inhibit the alternative pathway, which is most likely due to differences in the serum concentrations used to assess the three pathways (Fig. 6). In summary, SMSB4 seems to be a more potent inhibitor of all three pathways of the human complement system than SMSB3. While both serpins acted on several steps within the three pathways, SMSB4 interfered predominantly with the initial and progressing levels of the cascades, while SMSB3 exerted its strongest effects at the C9 level in all three pathways.

Due to the low protein purification yields of some of the SMS mutants, SMSB3/B was chosen as a model molecule to investigate the inhibitory mechanism against complement in deposition assays. SMSB3/B, containing the point mutation T368P in the RCL hinge region of the serpin, showed significantly different effects at the terminal complement pathway level (C9) in comparison with wild type SMSB3 (Fig. 6).

\section{SMSs Act Accumulatively on Deposition of Complement Component C9}

Since both serpins are present simultaneously in the mite gut we addressed how they acted on complement when present together. The lectin pathway was recently shown to play a role in scabies mite biology and a novel peritrophin localized in the mite gut was identified as a potential binding target of MBL [11]. As both serpins showed inhibition of this pathway we have assessed their collective effects in inhibiting the deposition of C9. A single dose of each serpin at a concentration of $5 \mu \mathrm{g} / \mathrm{ml}$ (110 nM SMSB3 or $93 \mathrm{nM}$ SMSB4) yielded a $43 \%$ and $30 \%$ decrease of C9 deposition respectively, while the combination of 

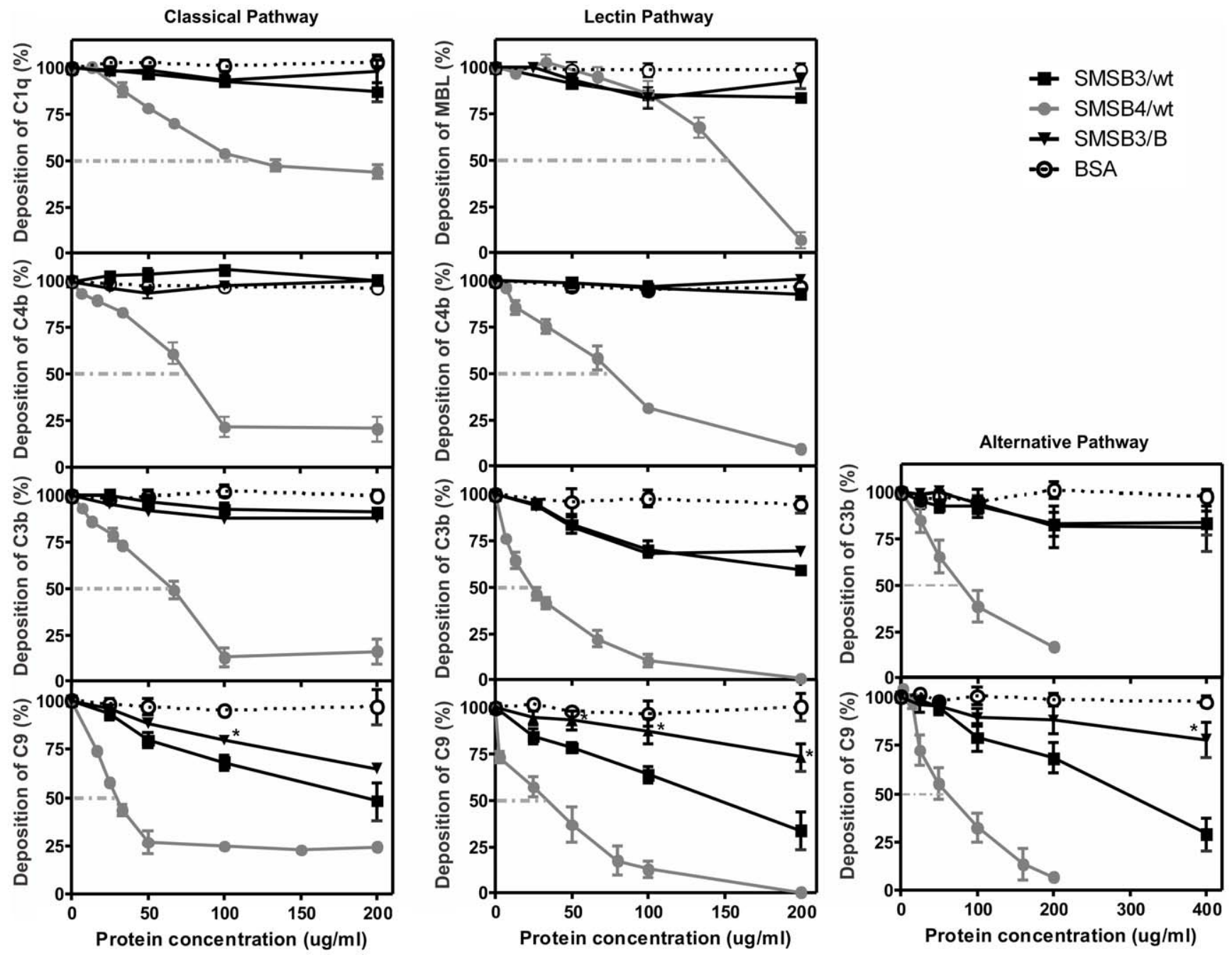

Figure 6. SMSs inhibit the classical, lectin and alternative pathway. Complement deposition assays were performed on microtiter plates coated with aggregated IgG (classical pathway), mannan (lectin pathway) and zymosan (alternative pathway) in presence or absence of scabies mite serpins, respectively. Shown are means \pm SEM of $n=4$ independent experiments, each performed in duplicate. The three pathways were measured using $1 \%$ (CP), $2 \%$ (LP) and 4\% (AP) NHS. Assays were performed at inhibitor protein concentrations of $25-400 \mu \mathrm{g} / \mathrm{ml}(0.5-8.6 \mu \mathrm{M})$ for SMSB3/wt and SMSB3/B and 10-200 $\mu \mathrm{g} / \mathrm{ml}(0.2-3.7 \mu \mathrm{M})$ for SMSB4/wt. Significant differences between wild type SMSB3 and the hinge mutant SMSB3/B $(* ; p<0.05)$. doi:10.1371/journal.pone.0040489.g006

both serpins at the same concentrations decreased C9 deposition by $66 \%$, thereby indicating additive effects (Fig. 7).

Digestion of SMSB3 by Human Neutrophil Elastase has no Effect on C9 Deposition in the Lectin Pathway

Elastase from recruited neutrophils may be present in the scabies mite infested skin during opportunistic bacterial infection. As the cleavage of SMSB3 by human neutrophil elastase could potentially be relevant for disease progression, we investigated whether cleavage of this serpin by elastase could alter the interaction with complement. For the lectin pathway, an increased concentration of serpin SMSB3 $(50 \mu \mathrm{g} / \mathrm{ml})$ was required to decrease C9 deposition by $40 \%$ under these conditions, but there was no significant difference in the effect on the deposition of complement component C9 between cleaved and whole SMSB3 (Fig. 8).

\section{SMSs Bind Directly to Several Complement Factors}

SMSB3 and SMSB4 revealed significant binding to a range of purified human complement factors, and showed differences in specificity and affinity (Fig. 9A and B). While both SMSs bound strongly to the purified C1 complex and its single components, several other serine proteases and plasma complement proteins of the three cascades reacted with both SMSs, suggesting alternative binding sites. The mutant SMSB3/B showed the same binding pattern as the active serpin (data not shown), indicating that binding can still occur, but conformational changes of the serpin molecule required for complement inhibition may be impaired. Interestingly, direct binding of both SMSs to complement factors C3 and C4 occurred only with the native forms, i.e. C3 and C4 were bound, but not the cleaved factors $\mathrm{C} 3 \mathrm{~b}$ and $\mathrm{C} 4 \mathrm{~b}$.

To confirm the direct binding of SMSs to human complement factors under more physiological conditions, additional binding assays were performed using NHS and immunodetection of the bound proteins (Fig. 9C). Typical hyperbolic curves were observed with increasing NHS concentrations. Direct binding was found 


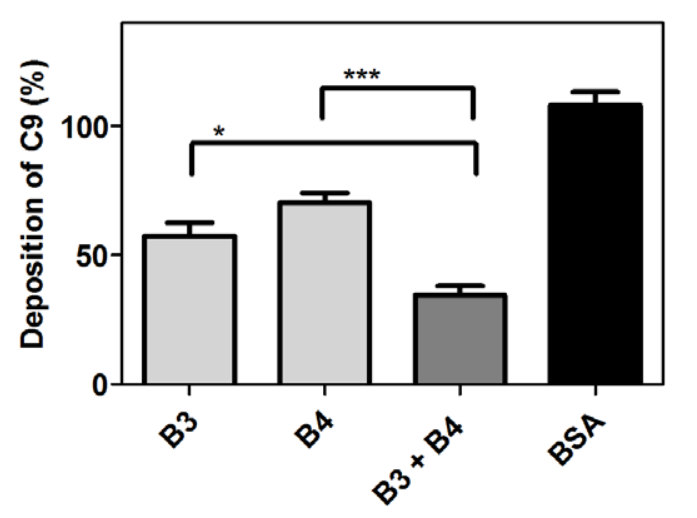

Figure 7. Additive effects of SMS B3 and SMSB4. Mannan was immobilized on microtiter plates and allowed to activate 4\% NHS containing $5 \mu \mathrm{g} / \mathrm{ml}$ of either serpin (110 nM SMSB3 or $93 \mathrm{nM}$ SMSB4) alone or mixed together. As a negative control BSA was used at a concentration of $10 \mu \mathrm{g} / \mathrm{ml}$. After $20 \mathrm{~min}$ of incubation the plates were washed and the deposited C9 was detected with specific antibodies. An average of three independent experiments is presented with bars indicating means \pm SEM. ${ }^{*} p<0.05,{ }^{* *} p<0.001$ by $t$ test (GraphPad Prism).

doi:10.1371/journal.pone.0040489.g007

between SMSB4 and the serine proteases $\mathrm{C} 1 \mathrm{r}$ and $\mathrm{C} 1 \mathrm{~s}$, respectively (Fig. 9C). In addition, SMSB4 bound to seven other complement factors (C1q, MBL, properdin, C3, C4, C6, and C8; Fig. 9C). The mechanism by which the serpin binds these nonprotease factors is unknown, but the data confirm the inhibition of the complement pathways at many levels, including the start of the cascades (Fig. 6).

Low amounts of non-specific binding occurred between SMSB3 and the $\mathrm{C} 1$ complement components at low NHS concentrations (Fig. 9C). These were not seen at higher concentrations. Experiments using NHS confirmed the observed inhibitory effects on the terminal pathway by revealing typical binding curves for three complement factors (C3, C4, C8; Fig. 9G) indicating high affinity binding for these proteins. None of these factors have a serine protease function.

\section{Interaction of Scabies Serpins with Human Complement Enzymes}

C1r or C1s, purified from human plasma, and recombinant MASP-1, MASP-2 or MASP-3 were incubated with SMSB3, SMSB4 or human C1-inhibitor and subsequently the samples were separated by SDS-PAGE (Fig. S2). As expected, C1s and C1r formed a higher MW band after incubation with human C1inhibitor, formed by the serpin interacting with the catalytic domain of these enzymes. However, the formation of the higher MW band was not seen with either of the scabies mite serpins when incubated with any of the complement proteases tested, indicating that the serpins were not able to form stable, covalently bound complexes with these proteases.

To investigate the interaction of the mite serpins with human MASP-1 and MASP-2, further increasing concentrations of purified recombinant MASP-1 or MASP-2 were incubated with SMB3 and SMB4 and analysed by SDS-PAGE. SMS B3 was cleaved by both MASP-1 and MASP-2, with higher concentrations of MASP-1 required to demonstrate the effect (Fig. S3). SMS B4 was unaffected by the enzymes and neither serpin could be shown to form an SDS-stable complex with the enzymes, indicating that they did not form the classical covalent enzymeserpin complex. In order to investigate whether the serpins were

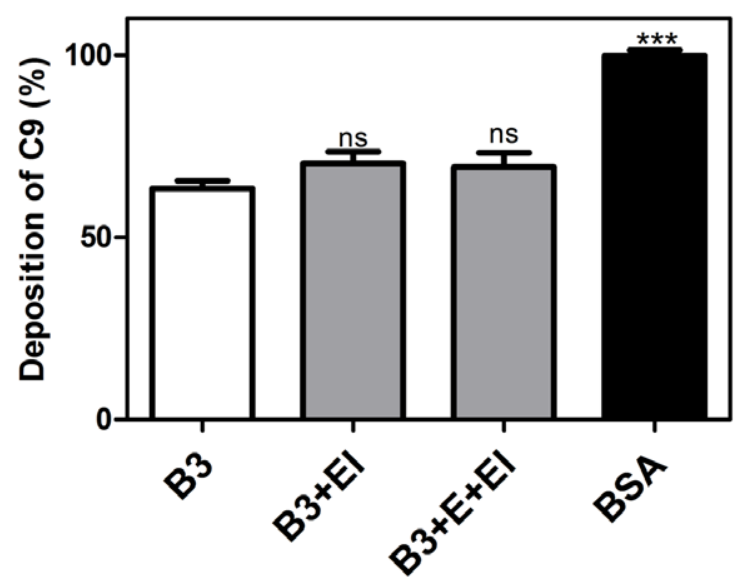

Figure 8. Digestion of SMSB3 by human neutrophil elastase has no effect on C9 deposition. SMSB3 was cleaved with human leukocyte elastase, following which the enzyme was inhibited by addition of $\mathrm{N}$-methoxysuccinyl-Ala-Ala-Pro-Val-chloromethyl ketone. Control reactions without addition of elastase $(E)$ and elastase inhibitor $\mathrm{N}$-methoxysuccinyl-Ala-Ala-Pro-Val-chloromethyl ketone were preformed under the same conditions. Mannan was immobilized on microtiter plates and allowed to activate $4 \%$ NHS containing $50 \mu \mathrm{g} / \mathrm{ml}$ SMSB3. As a negative control, BSA was used at a concentration of $10 \mu \mathrm{g} / \mathrm{ml}$. After a $20 \mathrm{~min}$ incubation the plates were washed and the deposited C9 was detected with specific antibodies. An average of three independent experiments is presented with bars indicating means \pm SEM. ${ }^{*} p<0.05,{ }^{* * *} p<0.001$ by $t$ test (GraphPad Prism).

doi:10.1371/journal.pone.0040489.g008

able to inhibit the enzymes, increasing concentrations of the serpins were added to constant amounts of the enzymes and residual activity was monitored using the substrate, Leu-Gly-ArgNHMec. No inhibition of enzyme activity was seen for either serpin with any of the enzymes (data not shown).

\section{Discussion}

In this study two novel SMSs were biochemically characterized and functionally analyzed. Both SMSs showed some typical properties of the serpin superfamily [51]. Enzyme assays demonstrating the inhibitory profile of both scabies mite serpins showed that the recombinant purified proteins were active serpins (Fig. 4), able to inhibit mammalian proteases. SMSB3 inhibited chymotrypsin (Fig. 4) by formation of covalent serpin/protease complexes, presumably executing the classical serpin mechanism. This was further supported by the finding that SMSB3 mutants A and $\mathrm{B}$ with the hinge sequence altered at position 14 did not inhibit chymotrypsin (Fig. 4). It has been established previously that a mutation of the $\mathrm{P} 14$ residue of the hinge sequence in serpins generally blocks loop insertion and partially or completely abolishes serine proteinase inhibitory activity [69], as the flexibility of the hinge is centered on the presence of an uncharged P14 residue [70].

Immunohistochemistry studies showed that serpins localized in the scabies mite gut (Fig. 3). Host serum is ingested into the mite gut $[9,68]$, and the presence of complement factors, such as Clq and $\mathrm{C} 9$, has been demonstrated [10,71]. It has been suggested that blood-feeding arthropods produce serpins that protect the gut from host circulatory proteases [52]. In line with this research, the discovery of complement-inhibitory serpins in the gut of scabies mites may add new aspects to our understanding of the scabies mite-host relationship. Apart from the gut, both serpin molecules were found in the mite feces, as shown for SMSB3 in Fig. 3, for 

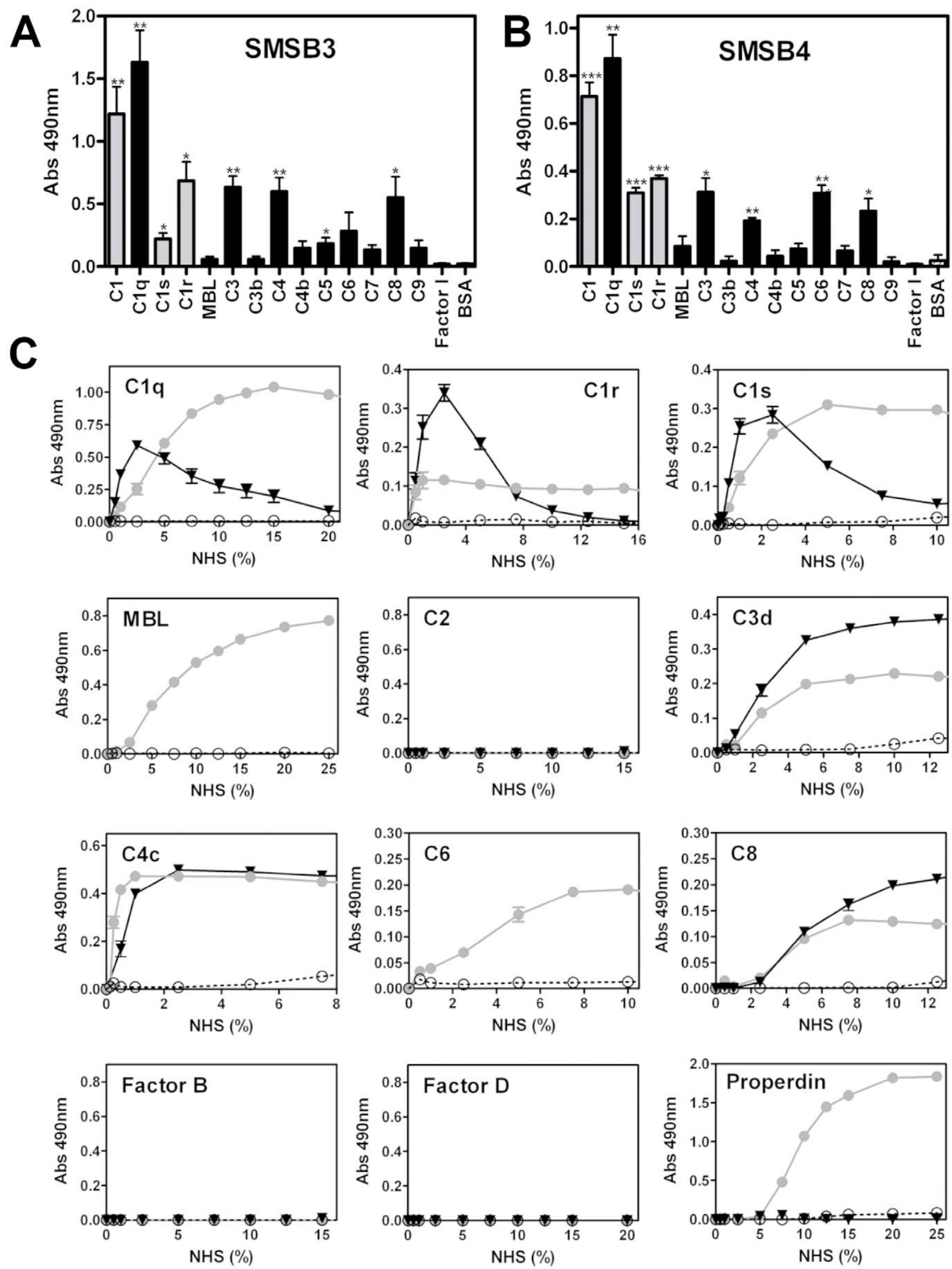
Figure 9. Direct binding of SMSs to various complement proteins. Microtiter plates were coated with various purified human complement proteins or BSA as a negative control and incubated with $20 \mu \mathrm{g} / \mathrm{ml} \mathrm{SMSB3}$ (A) or SMSB4 (B). Bound serpins were detected using specific polyclonal antibodies against SMSB3 and SMSB4. Shown are means \pm SEM of $n=3$ independent experiments. The statistical significance of differences between BSA and the rest of the data groups was estimated using one-way ANOVA. ${ }^{*}, p<0.05 ;{ }^{* *}, p<0.01 ;{ }^{* * *}, p<0.001$. Grey, serine proteases; black, other complement factors. C Direct binding of complement factors from NHS to SMSs. Increasing concentrations of NHS were added to wells coated with SMSB3 ( $\boldsymbol{\nabla}$, black), SMSB4 (, grey) or BSA as a negative control $(\bigcirc$, white) and bound complement factors were detected by specific antibodies. Shown are means \pm SEM of $n=3$ independent experiments measured in duplicates. NHS was tested from 0-100\%. Positive controls were used for complement proteins, where no binding to the SMSs was detectable confirming strong immunodetection of the complement factor on $1 \% \mathrm{NHS}$ coating.

doi:10.1371/journal.pone.0040489.g009

example. As house dust mite allergens are known to be highly active proteases after excretion [72,73] scabies mite gut molecules may be equally functional externally after being released into the upper epidermis, as well as internally within the gut.

SMSB4 exhibited effects as early as the initial and progressing steps of the complement cascades, while SMSB3 showed the strongest effects on the terminal pathway. Differences between protein concentrations needed in hemolytic and complement deposition assays were based on differences in NHS concentrations and other assay conditions. Clq is a pattern recognition molecule, which activates the classical pathway and assembles into a complex with its associated serine proteases, C1s and C1r [7]. The strong binding of SMSB4 to the components of the $\mathrm{Cl}$ complex (Clq, G1s and C1r; Figs. 9B and C) corresponds with the inhibitory effects at the $\mathrm{Clq}$ level demonstrated in deposition assays (Fig. 6). In contrast, the presumably non-specific binding between C1q and SMSB3 at low NHS concentrations (Fig. 9G) did not inhibit complement deposition (Fig. 6). Proteins binding to the complement factor $\mathrm{Clq}$ without affecting its function, or causing activation of complement instead, have been previously described [74-76].

C3 acts as the central molecule of the alternative pathway. Its hydrolyzed form is activated by the serine proteases B and D generating an initial C3 convertase, which cleaves C3 into C3a and C3b [7]. Properdin recognizes pathogen- or damageassociated molecular patterns and is involved in the initiation of the alternative pathway and the stabilization of AP convertases [77]. Thus, the binding of C3 and properdin by SMSB4 correlates with the strong inhibition at the C3b level in the alternative pathway (Fig. 6).

In contrast, SMSB3 only targeted non-serine proteases in human serum (Fig. 9C) and exhibited its strongest effect at the C9 level of the three pathways (Fig. 6) by interaction with C8, which takes part in the assembly of the terminal membrane attack complex along with the factors C5b, C6, C7 and C9.

An increasing number of serpins have been found to be noninhibitory towards proteases and show alternative binding mechanisms [51,52,78-80]. The changes in anti-complement activity of the mutants, in comparison with the wild type SMSs (Fig. 5), and the binding of both SMSs to complement factors without protease function (Fig. 9), suggested that possibly one or several exosites might be used to inhibit these proteins. While the ability of both SMSB3 hinge mutants A and B to inhibit bovine chymotrypsin in enzyme assays was impaired, most likely by inhibition of the serpin mechanism, the anti-complement activity of the hinge mutant SMSB3/A was not changed. In contrast, the hinge mutants SMSB3/B and SMSB4/F showed impaired anticomplement activity (Fig. 5), suggesting that domains outside the hinge region may have to be structurally changed to impair the anti-complement function of the serpins. In the SMSB3/B mutant, a proline residue was inserted into the hinge region. Proline insertions often disrupt the secondary structure and thus misfolding of the protein can occur and/or conformational changes necessary for binding or inhibitory mechanisms elsewhere in the molecule can be affected. No complex formation was seen with either of the scabies mite serpins when incubated with any of the complement proteases C1s, C1r, MASP-1, MASP-2 and MASP-3 tested, indicating that the mite serpins were not able to form stable, covalently bound complexes with these proteases. Thus, it appears that the effect of the mite serpins is not due to classical serpin inhibition of the serine proteases of the complement cascade. Based on the data presented here, it can be hypothesized that both the complement proteases tested and the non-proteolytic complement factors likely bind to an exosite of the SMSs or that the SMSs bind to exosites on the proteases, causing these proteins to be sterically inhibited from completing further binding interactions required for complement activation. However, the potential alternative binding mechanisms of the serpins to the complement proteases and factors have yet to be elucidated.

SMSs may act in concert with each other (Fig. 7) and with the catalytically inactive scabies mite serine proteases [10], which also inhibit human complement. It appears that the scabies mite has evolved a multitude of mechanisms to ensure human complement inactivation at all pathway levels, similarly to the broad range of anti-complement factors evolved by other pathogens [17,81]. We hypothesize that the compilation of mite complement inhibitors accumulates to high anti-complement activities in the confined space of the gut and epidermal burrows. Importantly, while complement factors are ingested by mites infesting human skin, MAC formation is not detected in the gut [71], suggesting that this anti-complement machinery may be very efficient in vivo. While prevention of gut lysis seems to be the obvious role of intestinal mite complement inhibitors, they may also act external to the mite and their presence in the epidermis may possibly have further consequences for the host. We have previously proposed that mite excretory proteins may effectively enhance the survival of scabies associated pathogenic bacteria by interfering locally with host complement [10]. The serpins described here may take part in this role. Further studies are needed to elucidate this hypothetical model of host, parasite and bacteria interactions in order to further the development of novel preventative and therapeutic strategies.

\section{Supporting Information}

Figure S1 Scabies mite serpins SMSB3 and SMSB4 do not interfere with the coagulation pathway. The functionality of the intrinsic and the extrinsic coagulation pathways in the presence of the two recombinant serine protease inhibitors, SMSB3 and SMSB4, was assessed by measuring the Activated Partial Thromboplastin Time (APTT) and the Prothrombin Time (PT). The dotted boxes represent reference ranges for clotting times of healthy donors.

(PDF)

Figure S2 Interaction of scabies mite serpins with human complement enzymes. $\mathrm{Cl}$ r $(\mathrm{hCl} / \mathrm{r})$ or $\mathrm{Cls}(\mathrm{hCl})$ purified from human plasma and recombinant MASP-1 (M1), MASP-2 (M2) or MASP-3 (M3) were incubated with SMSB3 (B3), SMSB4 (B4) or human C1-inhibitor (hCli) for $1 \mathrm{~h}$ at room 
temperature. Samples were electrophoresed on $10 \%$ SDS-PAGE as indicated in the labels above each lane. The positions of the catalytic chains of the enzymes are indicated [e.g. Clr (c)]. The positions of the complexes between hClr and hCls and hCli are also indicated.

(PDF)

Figure S3 Interaction of scabies mite serpins with human MASP-1 and MASP-2. Increasing concentrations of purified recombinant MASP-1 (M1) or MASP-2 (M2) were incubated with SMSB3 (B3) and SMSB4 (B4) for $1 \mathrm{~h}$ at room temperature. Samples were separated on 10\% SDS-PAGE as indicated in the labels above each lane shown. Molecular weight markers (Precision Plus Protein ${ }^{\mathrm{TM}}$ Dual Colour Standard, BIO RAD) are shown in the first lane at the left of each SDS-PAGE gel.

\section{References}

1. Hengge UR, Currie BJ, Jäger G, Lupi O, Schwartz RA (2006) Scabies: a ubiquitous neglected skin disease. The Lancet Infectious Diseases 6: 769-779.

2. Walton SF, Currie BJ (2007) Problems in diagnosing scabies, a global disease in human and animal populations. Clin Microbiol Rev 20: 268-279.

3. Clucas DB, Carville KS, Connors C, Currie BJ, Carapetis JR, et al. (2008) Disease burden and health-care clinic attendances for young children in remote aboriginal communities of northern Australia. Bull World Health Organ 86: 275-281.

4. Brook I (1995) Microbiology of secondary bacterial infection in scabies lesions. J Clin Microbiol 33: 2139-2140.

5. McDonald M, Currie BJ, Carapetis JR (2004) Acute rheumatic fever: a chink in the chain that links the heart to the throat? Lancet Infect Dis 4: 240-245.

6. Mounsey KE, Holt DC, McCarthy J, Currie BJ, Walton SF (2008) Scabies: molecular perspectives and therapeutic implications in the face of emerging drug resistance. Future Microbiology 3: 57-66.

7. Ricklin D, Hajishengallis G, Yang K, Lambris JD (2010) Complement: a key system for immune surveillance and homeostasis. Nat Immunol 11: 785-797.

8. Beckham SA, Boyd SE, Reynolds S, Willis C, Johnstone M, et al. (2009) Characterization of a serine protease homologous to house dust mite group 3 allergens from the scabies mite Sarcoptes scabiei. J Biol Chem 284: 3441334422.

9. Rapp CM, Morgan MS, Arlian LG (2006) Presence of host immunoglobulin in the gut of Sarcoptes scabiei (Acari: Sarcoptidae). J Med Entomol 43: 539-542.

10. Bergstrom FC, Reynolds S, Johnstone M, Pike RN, Buckle AM, et al. (2009) Scabies mite inactivated serine protease paralogs inhibit the human complement system. J Immunol 182: 7809-7817.

11. Mika A, Goh P, Holt DC, Kemp DJ, Fischer K (2011) Scabies mite peritrophins are potential targets of human host innate immunity. PLoS Negl Trop Dis 5: e1331.

12. Holt DC, Fischer K, Allen GE, Wilson D, Wilson P, et al. (2003) Mechanisms for a novel immune evasion strategy in the scabies mite sarcoptes scabiei: a multigene family of inactivated serine proteases. J Invest Dermatol 121: 1419 1424 .

13. Fischer K, Langendorf CG, Irving JA, Reynolds S, Willis C, et al. (2009) Structural mechanisms of inactivation in scabies mite serine protease paralogues. J Mol Biol 390: 635-645.

14. Zipfel PF, Wurzner R, Skerka C (2007) Complement evasion of pathogens: common strategies are shared by diverse organisms. Mol Immunol 44: 38503857 .

15. Lambris JD, Ricklin D, Geisbrecht BV (2008) Complement evasion by human pathogens. Nat Rev Microbiol 6: 132-142.

16. Schroeder H, Skelly PJ, Zipfel PF, Losson B, Vanderplasschen A (2009) Subversion of complement by hematophagous parasites. Dev Comp Immunol 33: 5-13.

17. Skelly PJ (2004) Intravascular schistosomes and complement. Trends Parasitol 20: $370-374$.

18. Skelly PJ, Alan Wilson R (2006) Making sense of the schistosome surface. Adv Parasitol 63: 185-284.

19. Parola P, Raoult D (2006) Tropical rickettsioses. Clin Dermatol 24: 191-200.

20. Parola P, Raoult D (2001) Ticks and tickborne bacterial diseases in humans: an emerging infectious threat. Clin Infect Dis 32: 897-928.

21. Nicholson WL, Sonenshine DE, Lane RS, Uilenberg G (2009) Ticks (Ixodida. In: Mullen GR, Durden LA, editors. Medical and Veterinary Entomology. 2nd edition ed. San Diego, CA: Academic Press. 493-541.

22. Francischetti IM, Sa-Nunes A, Mans BJ, Santos IM, Ribeiro JM (2009) The role of saliva in tick feeding. Front Biosci 14: 2051-2088.

23. Hovius JW, Levi M, Fikrig E (2008) Salivating for knowledge: potential pharmacological agents in tick saliva. PLoS Med 5: e43.

24. Steen NA, Barker SC, Alewood PF (2006) Proteins in the saliva of the Ixodida (ticks): pharmacological features and biological significance. Toxicon 47: 1-20.
(PDF)

\section{Acknowledgments}

The authors wish to thank Cassandra Lane and Yonghong Zhou for excellent technical assistance and Joanne Beggs, Advanced Scientist Core Coagulation Pathology, Queensland for expertise with coagulation experiments.

\section{Author Contributions}

Conceived and designed the experiments: AM CW RNP AMB DJK KF. Performed the experiments: AM FGM SLR VH GW DAP PMS LCW KF. Analyzed the data: AM RNP AMB DJK KF. Contributed reagents/ materials/analysis tools: RNP AMB DJK KF. Wrote the paper: AM RNP AMB DJK KF.

25. Valenzuela JG, Francischetti IM, Pham VM, Garfield MK, Mather TN, et al. (2002) Exploring the sialome of the tick Ixodes scapularis. J Exp Biol 205: 28432864 .

26. Nene V, Lee D, Quackenbush J, Skilton R, Mwaura S, et al. (2002) AvGI, an index of genes transcribed in the salivary glands of the ixodid tick Amblyomma variegatum. Int J Parasitol 32: 1447-1456.

27. Nene V, Lee D, Kang'a S, Skilton R, Shah T, et al. (2004) Genes transcribed in the salivary glands of female Rhipicephalus appendiculatus ticks infected with Theileria parva. Insect Biochem Mol Biol 34: 1117-1128.

28. Francischetti IM, My Pham V, Mans BJ, Andersen JF, Mather TN, et al. (2005) The transcriptome of the salivary glands of the female western black-legged tick Ixodes pacificus (Acari: Ixodidae). Insect Biochem Mol Biol 35: 1142-1161.

29. Ribeiro JM, Alarcon-Chaidez F, Francischetti IM, Mans BJ, Mather TN, et al. (2006) An annotated catalog of salivary gland transcripts from Ixodes scapularis ticks. Insect Biochem Mol Biol 36: 111-129.

30. Alarcon-Chaidez FJ, Sun J, Wikel SK (2007) Transcriptome analysis of the salivary glands of Dermacentor andersoni Stiles (Acari: Ixodidae). Insect Biochem Mol Biol 37: 48-71.

31. Francischetti IM, Mans BJ, Meng Z, Gudderra N, Veenstra TD, et al. (2008) An insight into the sialome of the soft tick, Ornithodorus parkeri. Insect Biochem Mol Biol 38: 1-21.

32. Mans BJ, Andersen JF, Francischetti IM, Valenzuela JG, Schwan TG, et al. (2008) Comparative sialomics between hard and soft ticks: implications for the evolution of blood-feeding behavior. Insect Biochem Mol Biol 38: 42-58.

33. Mans BJ, Andersen JF, Schwan TG, Ribeiro JM (2008) Characterization of antihemostatic factors in the argasid, Argas monolakensis: implications for the evolution of blood-feeding in the soft tick family. Insect Biochem Mol Biol 38: 22-41.

34. Francischetti IM, Meng Z, Mans BJ, Gudderra N, Hall M, et al. (2008) An insight into the salivary transcriptome and proteome of the soft tick and vector of epizootic bovine abortion, Ornithodoros coriaceus. J Proteomics 71: 493-512.

35. Chmelar J, Anderson JM, Mu J, Jochim RC, Valenzuela JG, et al. (2008) Insight into the sialome of the castor bean tick, Ixodes ricinus. BMC Genomics 9: 233.

36. Batista IF, Chudzinski-Tavassi AM, Faria F, Simons SM, Barros-Batestti DM, et al. (2008) Expressed sequence tags (ESTs) from the salivary glands of the tick Amblyomma cajennense (Acari: Ixodidae). Toxicon 51: 823-834.

37. Aljamali MN, Hern L, Kupfer D, Downard S, So S, et al. (2009) Transcriptome analysis of the salivary glands of the female tick Amblyomma americanum (Acari: Ixodidae). Insect Mol Biol 18: 129-154

38. Francischetti IM, Anderson JM, Manoukis N, Pham VM, Ribeiro JM (2011) An insight into the sialotranscriptome and proteome of the coarse bontlegged tick, Hyalomma marginatum rufipes. J Proteomics 74: 2892-2908.

39. Lawrie CH, Sim RB, Nuttall PA (2005) Investigation of the mechanisms of anticomplement activity in Ixodes ricinus ticks. Mol Immunol 42: 31-38.

40. Nunn MA, Sharma A, Paesen GC, Adamson S, Lissina O, et al. (2005) Complement Inhibitor of C5 Activation from the Soft Tick Ornithodoros moubata. J Immunol 174: 2084-2091.

41. Hepburn NJ, Williams AS, Nunn MA, Chamberlain-BanoubJC, Hamer J, et al. (2007) In Vivo Characterization and Therapeutic Efficacy of a C5-specific Inhibitor from the Soft Tick Ornithodoros moubata. J Biol Chem 282: 8292 8299.

42. Roversi P, Lissina O, Johnson S, Ahmat N, Paesen GC, et al. (2007) The structure of OMCI, a novel lipocalin inhibitor of the complement system. J Mol Biol 369: 784-793.

43. Mans BJ, Ribeiro JM (2008) Function, mechanism and evolution of the moubatin-clade of soft tick lipocalins. Insect Biochem Mol Biol 38: 841-852.

44. Valenzuela JG, Charlab R, Mather TN, Ribeiro JMC (2000) Purification, Cloning, and Expression of a Novel Salivary Anticomplement Protein from the Tick, Ixodes scapularis. J Biol Chem 275: 18717-18723.

45. Daix V, Schroeder H, Praet N, Georgin JP, Chiappino I, et al. (2007) Ixodes ticks belonging to the Ixodes ricinus complex encode a family of anticomplement proteins. Insect Mol Biol 16: 155-166. 
46. Schroeder H, Daix V, Gillet L, Renauld JC, Vanderplasschen A (2007) The paralogous salivary anti-complement proteins IRAC I and IRAC II encoded by Ixodes ricinus ticks have broad and complementary inhibitory activities against the complement of different host species. Microbes Infect 9: 247-250.

47. Couvreur B, Beaufays J, Charon C, Lahaye K, Gensale F, et al. (2008) Variability and action mechanism of a family of anticomplement proteins in Ixodes ricinus. PLoS ONE 3: e1400.

48. Tyson K, Elkins C, Patterson H, Fikrig E, de Silva A (2007) Biochemical and functional characterization of Salp20, an Ixodes scapularis tick salivary protein that inhibits the complement pathway. Insect Mol Biol 16: 469-479.

49. Tyson KR, Elkins C, de Silva AM (2008) A novel mechanism of complement inhibition unmasked by a tick salivary protein that binds to properdin. J Immunol 180: 3964-3968.

50. Kerr FK, Thomas AR, Wijeyewickrema LC, Whisstock JC, Boyd SE, et al. (2008) Elucidation of the substrate specificity of the MASP-2 protease of the lectin complement pathway and identification of the enzyme as a major physiological target of the serpin, C1-inhibitor. Mol Immunol 45: 670-677.

51. Gettins PG, Olson ST (2009) Exosite determinants of serpin specificity. J Biol Chem 284: 20441-20445.

52. Silverman GA, Whisstock JC, Bottomley SP, Huntington JA, Kaiserman D, et al. (2010) Serpins flex their muscle: I. Putting the clamps on proteolysis in diverse biological systems. J Biol Chem 285: 24299-24305.

53. Mulenga A, Sugino M, Nakajima M, Sugimoto C, Onuma M (2001) Tick encoded serine proteinase inhibitors (serpin); potential target antigens for tick vaccine development. J Vet Med Sci 63: 1063-1069.

54. Mulenga A, Tsuda A, Onuma M, Sugimoto C (2003) Four serine proteinase inhibitors (serpin) from the brown ear tick, Rhiphicephalus appendiculatus; cDNA cloning and preliminary characterization. Insect Biochem Mol Biol 33: 267-276.

55. Chalaire KC, Kim TK, Garcia-Rodriguez H, Mulenga A (2011) Amblyomma americanum (L.) (Acari: Ixodidae) tick salivary gland serine protease inhibitor (serpin) 6 is secreted into tick saliva during tick feeding. J Exp Biol 214: 665-673.

56. Mulenga A, Khumthong R, Chalaire KC (2009) Ixodes scapularis tick serine proteinase inhibitor (serpin) gene family; annotation and transcriptional analysis. BMC Genomics 10: 217

57. Mulenga A, Sugimoto C, Ingram G, Ohashi K, Misao O (2001) Characterization of two cDNAs encoding serine proteinases from the hard tick Haemaphysalis longicornis. Insect Biochem Mol Biol 31: 817-825.

58. Sugino M, Imamura S, Mulenga A, Nakajima M, Tsuda A, et al. (2003) A serine proteinase inhibitor (serpin) from ixodid tick Haemaphysalis longicornis; cloning and preliminary assessment of its suitability as a candidate for a tick vaccine. Vaccine 21: 2844-2851.

59. Levi A, Mumcuoglu K, Ingber A, Enk C (2011) Assessment of Sarcoptes scabiei viability in vivo by reflectance confocal microscopy. Lasers in Medical Science 26 : 291-292.

60. Beckham SA, Boyd SE, Reynolds S, Willis C, Johnstone M, et al. (2009) Characterization of a serine protease homologous to house dust mite group 3 allergens from the scabies mite Sarcoptes scabiei. Journal of Biological Chemistry 284: 34413-34422.

61. Rapp C, Morgan M, Arlian L (2006) Presence of host immunoglobulin in the gut of Sarcoptes scabiei (Acari: Sarcoptidae). J Med Entomol 43: 539-542.

62. Mika A, Goh P, Holt DC, Kemp DJ, Fischer K (2011) Scabies mite peritrophins are potential targets of human host innate immunity. PLoS Neglected Tropical Diseases 5: e1331.

63. Australian Government NHMRC (2004) Australian code of practice for the care and use of animals for scientific purposes. 7th edition ed. 1-84.
64. Fischer K, Holt DC, Harumal P, Currie BJ, Walton SF, et al. (2003) Generation and characterization of cDNA clones from Sarcoptes scabiei var. hominis for an expressed sequence tag library: identification of homologues of house dust mite allergens. American Journal of Tropical Medicine and Hygiene 68: 61-64.

65. Bradford MM (1976) Rapid and Sensitive Method for Quantitation of Microgram Quantities of Protein Utilizing Principle of Protein-Dye Binding. Analytical Biochemistry 72: 248-254.

66. Tenner AJ, Lesavre PH, Cooper NR (1981) Purification and radiolabeling of human C1q. J Immunol 127: 648-653.

67. Crossley LG, Porter RR (1980) Purification of the human complement control protein C3b inactivator. Biochem J 191: 173-182.

68. Willis C, Fischer K, Walton SF, Currie BJ, Kemp DJ (2006) Scabies mite inactivated serine protease paralogues are present both internally in the mite gut and externally in feces. Am J Trop Med Hyg 75: 683-687.

69. Lawrence DA, Olson ST, Palaniappan S, Ginsburg D (1994) Serpin reactive center loop mobility is required for inhibitor function but not for enzyme recognition. J Biol Chem 269: 27657-27662.

70. Schick C, Bromme D, Bartuski AJ, Uemura Y, Schechter NM, et al. (1998) The reactive site loop of the serpin SCCA1 is essential for cysteine proteinase inhibition. Proc Natl Acad Sci U S A 95: 13465-13470.

71. Mika A, Goh P, Holt D, Kemp DJ, Fischer K (2011) Scabies Mite Peritrophin are Potential Targets of Human Host Innate Immunity. PLoS Negl Trop Dis in press.

72. Wan H, Winton HL, Soeller C, Tovey ER, Gruenert DC, et al. (1999) Der p 1 facilitates transepithelial allergen delivery by disruption of tight junctions. J Clin Invest 104: 123-133.

73. Stewart GA, Ward LD, Simpson RJ, Thompson PJ (1992) The group III allergen from the house dust mite Dermatophagoides pteronyssinus is a trypsinlike enzyme. Immunology 75: 29-35.

74. Alberti S, Marques G, Camprubi S, Merino S, Tomas JM, et al. (1993) C1q binding and activation of the complement classical pathway by Klebsiella pneumoniae outer membrane proteins. Infect Immun 61: 852-860.

75. Sjoberg AP, Manderson GA, Morgelin M, Day AJ, Heinegard D, et al. (2009) Short leucine-rich glycoproteins of the extracellular matrix display diverse patterns of complement interaction and activation. Mol Immunol 46: 830-839.

76. Manderson GA, Martin M, Onnerfjord P, Saxne T, Schmidtchen A, et al. (2009) Interactions of histidine-rich glycoprotein with immunoglobulins and proteins of the complement system. Mol Immunol 46: 3388-3398.

77. Chen H, Ricklin D, Hammel M, Garcia BL, McWhorter WJ, et al. (2010) Allosteric inhibition of complement function by a staphylococcal immune evasion protein. Proc Natl Acad Sci U S A 107: 17621-17626.

78. Higgins WJ, Fox DM, Kowalski PS, Nielsen JE, Worrall DM (2010) Heparin enhances serpin inhibition of the cysteine protease cathepsin L.J Biol Chem 285: $3722-3729$.

79. Zhou A, Wei Z, Stanley PL, Read RJ, Stein PE, et al. (2008) The S-to-R transition of corticosteroid-binding globulin and the mechanism of hormone release. J Mol Biol 380: 244-251.

80. Whisstock JC, Silverman GA, Bird PI, Bottomley SP, Kaiserman D, et al. (2010) Serpins flex their muscle: II. Structural insights into target peptidase recognition, polymerization, and transport functions. J Biol Chem 285: 24307-24312.

81. Rooijakkers SH, van Strijp JA (2007) Bacterial complement evasion. Mol Immunol 44: 23-32.

82. Schechter I, Berger A (1967) On the size of the active site in proteases. I. Papain. Biochem Biophys Res Commun 27: 157-162. 